\title{
An ab initio study of oxide ion dynamics in type-II $\mathrm{Bi}_{3} \mathrm{NbO}_{7}$
}

\author{
M. Krynski, ${ }^{a^{*}}$ W. Wrobel, ${ }^{a^{*}}$ J. R. Dygas, ${ }^{a}$ M. Malys, ${ }^{a}$ F. Krok ${ }^{a}$ and I. Abrahams ${ }^{b}$
}

${ }^{a}$ Faculty of Physics, Warsaw University of Technology, Koszykowa 75, 00-662 Warsaw, Poland.

${ }^{\mathrm{b}}$ Materials Research Institute, Department of Chemistry and Biochemistry, School of Biological and Chemical Sciences, Queen Mary University of London, Mile End Road, London E1 4NS, U.K.

*Corresponding authors: $\quad$ W. Wrobel e-mail: wrobel@if.pw.edu.pl

M. Krynski e-mail: krynski.marcin@ outlook.com

\begin{abstract}
Oxide ion dynamics in the type-II phase of $\mathrm{Bi}_{3} \mathrm{NbO}_{7}$ have been studied using a series of DFT molecular dynamics calculations. Coordination numbers and angular distribution functions for both bismuth and niobium cations were analysed. A strong preference for octahedral coordination of niobium cations was observed. This has the effect of reducing the overall number of mobile vacancies in the system. Energy landscapes for the system revealed lowenergy barriers for oxide ion jumps in the <100> direction. Whilst oxide ion jumps were found to occur around both cations, only around bismuth cations do the jumps result in significant long-range movement of oxide ions, with those around niobium cations predominantly associated with dynamics of the niobate octahedra.
\end{abstract}

\section{Keywords:}

Bismuth oxide; bismuth niobium oxide; fluorite structure, DFT calculations; molecular dynamics simulations, oxide ion conductivity, trapping mechanism. 


\section{Introduction}

$\delta-\mathrm{Bi}_{2} \mathrm{O}_{3}$, exhibits the highest known oxide ion conductivity of any solid, with a value of $c a$. $1 \mathrm{~S} \mathrm{~cm}^{-1}$ at around $1000 \mathrm{~K}^{1}$ This high conductivity is related to the high vacancy concentration in the oxide ion sublattice, the high polarizability of the cation sublattice, as well as the three-dimensional conduction pathways of the defect fluorite structure adopted by $\delta$ - $\mathrm{Bi}_{2} \mathrm{O}_{3}$. Below $1000 \mathrm{~K}$, phase transitions to lower symmetry polymorphs, $\alpha, \beta$ and $\gamma$, occur depending on cooling rate. ${ }^{2}$ These phase transitions result in dramatic decreases in ionic conductivity of up to three orders of magnitude.

Stabilization of the $\delta-\mathrm{Bi}_{2} \mathrm{O}_{3}$ type phase to lower temperatures has been the subject of much research. It has been shown that partial substitution of $\mathrm{Bi}^{3+}$, by a variety of isovalent and aliovalent cations, can preserve the high temperature fluorite face centred cubic (fcc) phase to room temperature. ${ }^{3-5}$ Depending on the extent of the substitution and the nature of the substituent cation, the disorder present in $\delta-\mathrm{Bi}_{2} \mathrm{O}_{3}$ may be preserved, ordering may occur resulting in a superlattice of the fluorite subcell, distortions of the fluorite cell may be stabilized or significantly different structures may arise. Invariably, this leads to lower ionic conductivity than in pure $\delta-\mathrm{Bi}_{2} \mathrm{O}_{3}$. The type of substituent cation, its concentration, valence state, ionic radius and preferred coordination geometry alter the defect and electronic structure of the system, thus affecting electrical conductivity. Using an ab initio modelling approach, we have shown, ${ }^{6}$ that in the case of yttrium substituted bismuth oxide, $\delta-\mathrm{Bi}_{3} \mathrm{YO}_{6}$, yttrium ions act as trapping centres, for mobile oxide ions located in sites surrounded by two or three yttrium ions, with high oxide ion site occupancy, as well as long residence times are observed.

Substitution of $\mathrm{Bi}^{3+}$ by $\mathrm{Nb}^{5+}$ in the binary system $\mathrm{Bi}_{2} \mathrm{O}_{3}-\mathrm{Nb}_{2} \mathrm{O}_{5}$ results in a number of ordered and distorted fluorite phases. ${ }^{7-16}$ The phases that appear in this system were classified by Zhou into four principal types (I to IV). ${ }^{14}$ Compositions approximating to $\mathrm{Bi}_{3} \mathrm{NbO}_{7}$ (corresponding to $\mathrm{Bi} 25 \%$ substitution) exhibit unusual polymorphism, with the tetragonally ordered phase (type-III) stable between $1073 \mathrm{~K}$ and $1173 \mathrm{~K}$ and the pseudo-cubic type-II phase evident above and below this temperature range. ${ }^{12,13}$ The type-II structure is characterized by a superlattice, which shows a complex three-dimensional incommensurate modulation, but can be satisfactorily modelled using the fcc fluorite subcell. ${ }^{17,18}$ Ling et al. ${ }^{16}$ have recently resolved the incommensurately ordered structure of the type-II phase to reveal chains and clusters of niobate octahedra, which result in pyrochlore type regions in the fluorite matrix. These linked niobate polyhedra are believed to be responsible for a significant 
electronic contribution to total conductivity at low temperatures, perhaps through a polaron hopping mechanism. ${ }^{19}$

In type-II $\mathrm{Bi}_{3} \mathrm{NbO}_{7}$, the nominal vacancy concentration of one vacancy per cation is half that in $\delta-\mathrm{Bi}_{2} \mathrm{O}_{3}$. Subvalent substitution of $\mathrm{Nb}^{5+}$ in $\mathrm{Bi}_{3} \mathrm{NbO}_{7}$ increases the nominal vacancy concentration and ionic conductivity, as seen for example in the $\mathrm{Bi}_{3} \mathrm{YO}_{6}-\mathrm{Bi}_{3} \mathrm{NbO}_{7},{ }^{17,18}$ $\mathrm{Bi}_{3} \mathrm{YbO}_{6}-\mathrm{Bi}_{3} \mathrm{NbO}_{7}{ }^{20}$ and $\mathrm{Bi}_{3} \mathrm{ZrO}_{6.5}-\mathrm{Bi}_{3} \mathrm{NbO}_{7}{ }^{21}$ pseudo-binary systems. However, oxide ion vacancy concentration is not the only factor which influences ionic conductivity. For example $\mathrm{Bi}_{3} \mathrm{TaO}_{7}$, which has the same nominal vacancy concentration as $\mathrm{Bi}_{3} \mathrm{NbO}_{7}$, exhibits lower ionic conductivity. $^{22}$

We have recently studied the influence of isovalent substitution on the defect and electronic structure of bismuth oxide in the system $\mathrm{Bi}_{3} \mathrm{YO}_{6}$, using ab initio DFT studies. ${ }^{6,23}$ Here, we extend these studies to substitution by a supervalent cation, with special attention to the preferred coordination environment and influence of the substituting cation. Calculations are based on the average fluorite subcell model of type-II $\mathrm{Bi}_{3} \mathrm{NbO}_{7}$, as previously described. ${ }^{17,18}$

\section{Methodology}

$A b$ initio molecular dynamics simulations on $\mathrm{Bi}_{3} \mathrm{NbO}_{7}$ were performed using density functional theory (DFT) calculations. The Vienna Ab-initio Simulation Package (VASP) was used ${ }^{24-27}$ for calculations, with the generalized gradient approximation of the Perdew-BurkeErnzerhof ${ }^{28}$ parameterizations of exchange-correlation potential. Valence electron (5 for Bi; 11 for $\mathrm{Nb}$ and 6 for $\mathrm{O}$ ) potentials were described using the projector augmented wave approach. ${ }^{29}$ All elements in the system were simulated using standard pseudo-potentials. Interaction forces in the system were calculated using the Hellmann-Feynman theorem ${ }^{30,31}$ and the kinetic energy was controlled by means of the Nose-Hoover thermostat. ${ }^{32,33}$ The sampling of the Brillouin zone was performed using the Monkhorst-Pack scheme. ${ }^{34}$ Optimization to obtain stability of the total energy was performed to determine cut-off parameters. A $450 \mathrm{eV}$ cut-off energy for the plane wave basis set ${ }^{26,27}$ was used and the global break condition for the electronic SC-loop was set to $10^{-4}$. All calculations were carried out under periodic boundary conditions in $2 \times 2 \times 2$ supercells, containing eight stoichiometric units. Structure relaxation and molecular dynamics calculations were performed with a $2 \times 2$ 
$\times 2 \mathrm{k}$-mesh and a $1 \times 1 \times 1 \mathrm{k}$-mesh, respectively. Molecular dynamics simulations were carried out at temperatures of $1223 \mathrm{~K}, 1273 \mathrm{~K}, 1323 \mathrm{~K}$ and $1373 \mathrm{~K}$. To improve statistics of ion movements and to achieve a quasi-random distribution of ions in the system, three parallel sets of calculations were performed at each temperature. For every run, different initial, quasirandom distributions of cations, as well as random distributions of oxide ion vacancies were used. Atomic positions and initial lattice parameters were based on the results of combined analysis of X-ray and neutron scattering data, using the average fluorite subcell model of type-II $\mathrm{Bi}_{3} \mathrm{NbO}_{7}{ }^{17,18}$ Bismuth and niobium cations were placed initially at the $4 a$ crystallographic sites of the $F m-3 m$ space group, while the oxide ions were placed in the $8 c$ sites. MD calculations were performed over a total time of $70 \mathrm{ps}$, with a time step of $5 \mathrm{fs}$. The first $10 \mathrm{ps}$ of each MD simulation were excluded from the data analysis, to minimize the influence of initial thermodynamic equilibration of the simulated system.

\section{Results and discussion}

Ab initio molecular dynamics calculations were performed in order to investigate the oxide ion transport mechanism and structural properties of type- $\mathrm{II} \mathrm{Bi}_{3} \mathrm{NbO}_{7}$. The time dependence of the oxide ion mean square displacement (MSD) is presented in Fig. 1. There is a visible increase in the slope of the MSD plots, indicative of an increase in the diffusion coefficient with temperature. The value of the diffusion coefficient at $1223 \mathrm{~K}$ was found to be $0.23 \times 10^{-9}$ $\mathrm{m}^{2} \mathrm{~s}^{-1}$, and can be compared to values of $1 \times 10^{-9} \mathrm{~m}^{2} \mathrm{~s}^{-1}$ and $0.27 \times 10^{-9} \mathrm{~m}^{2} \mathrm{~s}^{-1}$ at $1023 \mathrm{~K}$, calculated from $a b$ initio molecular dynamics studies of $\delta-\mathrm{Bi}_{2} \mathrm{O}_{3}{ }^{35}$ and $\delta-\mathrm{Bi}_{3} \mathrm{YO}_{6}{ }^{6}{ }^{6}$ respectively. Diffusion in type-II $\mathrm{Bi}_{3} \mathrm{NbO}_{7}$ is found to be significantly lower than in other studied bismuth based compounds, which is consistent with the relatively low ionic conductivity of $\mathrm{Bi}_{3} \mathrm{NbO}_{7}$ measured using a.c. impedance spectroscopy. ${ }^{22}$

Molecular dynamics results were also used to analyse the distribution of individual ions in the studied system over the total simulation time. Fig. 2 shows individual pair distribution functions $\left(g_{i-j}(r)\right)$ for $\mathrm{Nb}-\mathrm{O}, \mathrm{Bi}-\mathrm{O}$ and $\mathrm{O}-\mathrm{O}$ pairs, determined as averages over three parallel calculations, at a temperature of $1223 \mathrm{~K}$. The $\mathrm{O}-\mathrm{O}$ function is almost featureless for distances longer than $c a .3 .5 \AA$, indicative of a high degree of disorder in the oxide ion sublattice. The noticeable difference between $\mathrm{Bi}-\mathrm{O}$ and $\mathrm{Nb}-\mathrm{O}$ patterns is mostly reflected in a significantly shorter contact distance in the latter case. This difference can be explained in terms of the much smaller ionic radius of $\mathrm{Nb}^{5+}$ compared to $\mathrm{Bi}^{3+}(r=0.64 \AA$ and $1.17 \AA$, for 
the ions in six and eight coordinations, respectively $\left.{ }^{36}\right)$. The narrower width of the first $g_{\mathrm{M}-\mathrm{O}}(r)$ peak for $\mathrm{Nb}-\mathrm{O}$ is consistent with a more regular coordination environment for $\mathrm{Nb}$ compared to that for $\mathrm{Bi}$.

The average oxygen coordination number $(\mathrm{CN})$ for bismuth is higher than that for niobium, with values of 7.18 and 6.01, respectively (Table 1). These values were calculated by integrating to the first deep minimum in the respective $g_{\mathrm{M}-\mathrm{O}}(r)$ functions, with cut-off distances of $3.4 \AA$ for $\mathrm{Bi}-\mathrm{O}$ and $2.9 \AA$ for $\mathrm{Nb}-\mathrm{O}$. The modal and mean contact distances and coordination numbers are compared with mean distances obtained from crystallographic analyses of the type-II and type-III structures in Table 1. The mean values compare well with those from the crystallographic studies at ambient temperatures. The modal Bi-O contact distance is significantly shorter than the mean value, which is indicative of the distorted coordination geometry adopted by bismuth in this system, caused by the stereochemical activity of the $6 s^{2}$ lone pair of electrons, with short bonding contacts and a number of longer essentially non-bonding interactions. The average coordination number for niobium was found to be almost exactly six in the present study, in good agreement with the known preference for pentavalent niobium to adopt six-coordinate geometry in oxides ${ }^{37}$ and is consistent with the most recent crystallographic study of the type-II structure. ${ }^{16}$ The local environment of every cation was analysed over the total time of the simulations and the resulting coordination number distributions are presented as histograms in Fig. 3. As indicated by the relatively narrow $g_{\mathrm{Nb}-\mathrm{O}}$ distribution (Fig. 2), niobium adopts, almost exclusively, sixcoordination with oxide ions. In the case of bismuth, the average site coordination number is a weighted sum of $\mathrm{CN}=7$ and $\mathrm{CN}=8$, with a smaller contribution of $\mathrm{CN}=6$. Interestingly, the observed distributions of cation coordination numbers are almost temperature independent in the studied range.

In order to shed more light on the coordination geometries adopted by bismuth and niobium, it is helpful to break down the $g_{\mathrm{M}-\mathrm{O}}$ pair distributions shown in Fig. 2 into the individual $\mathrm{M}-\mathrm{O}_{i}$ distributions for the eight closest oxide ions $(i=1$ to 8$)$. These distributions at $1223 \mathrm{~K}$ are plotted in Fig. 4, with the corresponding mean and modal values shown in Fig. 5. In the case of niobium, there is a linear increase in the position of the mean contact distance up to the $5^{\text {th }}$ contact, while that for the modal contact distance shows linearity up to the $6^{\text {th }}$ contact. Both mode and mean values for the $7^{\text {th }}$ and $8^{\text {th }}$ contacts, are at distances longer than 3 $\AA$, and these can be considered as non-bonding interactions. These results are consistent with niobium showing predominantly six-coordination, with a small proportion of five-coordinate 
polyhedra, as seen in Fig. 3. In the case of bismuth, the mean and modal contact distances show linear increases up to the $4^{\text {th }}$ and $5^{\text {th }}$ contacts, respectively. The deviation from linearity seen in both the mode and mean plots for $\mathrm{Bi}^{-} \mathrm{O}_{i}$ reflects the range of coordination numbers seen in Fig. 3. Many of the average $\mathrm{Bi}^{-} \mathrm{O}_{i}$ distances in Fig. 5 lie well above the sum of the ionic radii of $2.55 \AA$ (assuming eight-coordination for $\mathrm{Bi}^{3+}$ and four-coordination for $\mathrm{O}^{2-}{ }^{36}$ ), suggesting that these longer contacts are essentially non-bonding interactions.

Fig. 6 shows a typical oxide ion density profile in the $\langle 110\rangle$ plane, constructed from data over the total simulation time at $1223 \mathrm{~K}$. In the ideal fluorite structure, oxide ions are distributed over the $8 c$ sites in the $F m-3 m$ cell, which are indicated by the intersections of the dotted grid lines in Fig 6. In the studied system, the highest oxide ion densities are observed close to these sites. However, some oxide ion density is noticeably shifted away from these ideal sites (highlighted by red circles in Fig. 6) and is located around the niobium cations. This shifted oxide ion density correlates with the occupancy of the $32 f$ site in the $F m-3 m$ cell, as is seen in the crystallographic studies using the fluorite subcell model. ${ }^{17,18}$ An iso-surface representation of the anion density collapsed onto a single unit cell is shown in Fig. 7a and is compared to that for the previously studied compound, $\delta-\mathrm{Bi}_{3} \mathrm{YO}_{6}{ }^{6}$ (Fig. 7b). In the latter case, the ionic density shows a distribution shifted towards the apices of the tetrahedral sites in the fluorite structure. In the case of $\mathrm{Nb}$ substituted $\mathrm{Bi}_{2} \mathrm{O}_{3}$, the shift away from the centre of the $8 c$ site is more pronounced, indicative of greater disorder in the oxide ion sublattice. This is consistent with crystallographic studies, ${ }^{17,18}$ which show oxide ion scattering within the fluorite tetrahedral cavities is best described by occupation of the $32 f$ site alone, rather than a distribution between $32 f$ and $8 c$ sites as seen in $\delta-\mathrm{Bi}_{3} \mathrm{YO}_{6} \cdot{ }^{38}$

The nearest neighbour angular distribution functions, $A_{\mathrm{O}-\mathrm{M}-\mathrm{O}}(\theta)$, for bismuth and niobium atoms are presented in Fig. 8. In the $A_{\mathrm{O}-\mathrm{Bi}-\mathrm{O}}(\theta)$ distribution, three broad peaks centred at $\mathrm{ca} .73^{\circ}, 107^{\circ}$ and $165^{\circ}$ can be distinguished, characteristic of distorted cubic geometry (Fig. 9a), corresponding to edge, face diagonal and body diagonal alignments of oxide ions around the bismuth atoms. The broadness of these peaks is related not only to thermal vibration, but also reflects the range of coordination numbers exhibited by bismuth (Fig. 3). In the case of niobium, the $A_{\mathrm{O}-\mathrm{Nb}-\mathrm{O}}(\theta)$ distribution exhibits two maxima at $c a .92^{\circ}$ and $168^{\circ}$, consistent with a distorted octahedral coordination environment (Fig. 9b). 
The strong preference for niobium cations to adopt an octahedral coordination environment in type-II $\mathrm{Bi}_{3} \mathrm{NbO}_{7}$, as manifested in both the average coordination number and the angular distribution functions, has the effect of reducing the number of mobile vacancies, which results in high oxide ion site occupancy values around bismuth cations. This has the consequence of reducing long-range oxide ion movements in this system.

In order to examine the influence of the substituent cations on oxide ion dynamics, the local environment of each oxide ion in the model was analysed. In our previous study on $\delta$ $\mathrm{Bi}_{3} \mathrm{YO}_{6},{ }^{6}$ which shows a disordered defect fluorite structure, this was achieved by dividing the $2 \times 2 \times 2$ supercell into 64 separate compartments (octants), centred on the ideal $8 c$ oxide ion sites. Thus each octant had four cations arranged tetrahedrally on four corners of each octant, resulting in octants with between 0 and 4 substituent cations at the vertices. However, in the present system, this approach is not entirely appropriate, since significant oxide ion density is shifted away from the ideal $8 c$ site, as confirmed not only in the present study (Figs. 6 and 7a), but also in the crystallographic studies. ${ }^{17,18}$ An alternative approach, which overcomes this problem, is to characterize each oxide ion site at the centre of four nearest neighbour cations (Fig. 10). Similar approaches have been adopted for analysis of vacancy distributions in other systems. ${ }^{39}$ Fig. 11 shows the variation of oxide ion site occupancy (i.e. the fraction of the total simulation time, when the oxide ion site is occupied by any oxide ion) with the number of $\mathrm{Nb}$ atoms $(n)$ in the oxide coordination sphere. The fractional occupancy of oxide ion sites with no niobium neighbours is very high, with a value of $c a .0 .95$ at all investigated temperatures. This occupancy generally decreases as $n$ increases at all studied temperatures, with some discrepancies at the highest value of $n$. Similarly, oxide ion site residence time, $\tau_{n}$, can be defined as the average time that oxide ions spend in a specific oxide ion site surrounded by $n$ niobium dopant cations. Site residence time shows a general decrease with increasing value of $n$ as well as with increasing temperature, as shown in Fig. 12.

The energy distribution landscape can be derived from the ionic density map assuming the Boltzmann distribution:

$$
N_{x}=N_{0} \cdot e^{-\frac{\Delta E}{k T}}
$$


where $N_{x}$ represents the number of times that oxide ions were present at position $x, N_{0}$ is the number of times that oxide ions were present at the point of highest ionic density, $k$ is the Boltzmann constant and $T$ is the temperature.

Fig. 13 shows energy distribution landscapes in the $<110>$ plane for type- $\mathrm{II}_{3} \mathrm{Bi}_{3} \mathrm{NbO}_{7}$ at $1223 \mathrm{~K}$. The energy landscape around bismuth (Fig. 13a) appears more symmetrical compared to that around niobium (Fig. 13b), reflecting greater disorder around niobium cations. The energy barriers for oxide ion jumps in the bismuth cation surrounding were found to be $0.41 \mathrm{eV}$ and $0.68 \mathrm{eV}$ for jumps in the $\langle 100\rangle$ and $\langle 110\rangle$ directions, respectively, while the energy barriers for oxide ions in the niobium coordination sphere were $0.22 \mathrm{eV}$ and 0.55 $\mathrm{eV}$ for oxide ion jumps in these respective directions. The overall average jump barriers in these directions were found to be $0.38 \mathrm{eV}$ and $0.59 \mathrm{eV}$, respectively. Interestingly, the analogous values calculated for the $\delta-\mathrm{Bi}_{3} \mathrm{YO}_{6}$ system are noticeably higher $(0.44 \mathrm{eV}$ and 0.86 $\mathrm{eV}$ for the $\langle 100\rangle$ and $\langle 110\rangle$ directions, respectively), despite $\delta-\mathrm{Bi}_{3} \mathrm{YO}_{6}$ showing significantly higher ionic conductivity than $\mathrm{Bi}_{3} \mathrm{NbO}_{7}{ }^{6}$

In order to explain this apparent anomaly, it is helpful to examine the oxide ion dynamics in this system. Traces of oxide ion movements, over the total simulation time, show that a significant number of ion jumps appear in the niobium coordination sphere. Fig. 14 shows an iso-surface representation of oxide ion density in the niobium coordination sphere over the total simulation time. It is evident that while oxide ion density in the equatorial plane shows significant delocalization, consistent with extensive motion in that plane, the apical oxide ions remain much more localized. This reflects the average crystallographic model, ${ }^{17,18}$ where two types of oxide ion position were found, one located in the tetrahedral site of the ccp lattice and the other in an interstitial site, linearly coordinated to two cations. The observed local motion of oxide ions around the niobium cations is indicative of some dynamics of the niobate octahedra. Table 2 shows that over the studied temperature range, the majority of oxide ion jumps in the system appear to involve oxide ions in the $\mathrm{Nb}^{5+}$ coordination sphere. The ratio between translational jumps (ones that involve a jump from one cation coordination sphere to that of a neighbouring cation) and rotational jumps (ones that occur within the coordination sphere of a particular cation) is plotted for the two types of cation in this system in Fig. 15. It is evident that the translational:rotational jump ratio around bismuth cations is approximately three times greater than that around niobium cations and that this varies little with temperature over the range studied. The results show that the majority of jumps around bismuth cations contribute to oxide ion diffusion, whilst those around niobium cations have a roughly equal probability of contribution to long-range (translational) or short- 
range (rotational) movement of oxide ions. This kind of local motion of oxide ions in the niobium coordination sphere (dynamics of niobate octahedra) is not reflected in the mean square displacement (Fig.1) and thus has a low impact on the total electrical conductivity of type-II $\mathrm{Bi}_{3} \mathrm{NbO}_{7}$. Thus, many of the vacancies seen in oxide ion sites neighboured by niobium cations are effectively trapped in the niobium coordination sphere. This vacancy trapping can be compared to that found around yttrium in $\delta-\mathrm{Bi}_{3} \mathrm{YO}_{6}{ }^{6}$

Iso-surfaces of the electron density in the bismuth and niobium cation surroundings are presented in Fig. 16. The electron density value was chosen to demonstrate the asymmetry of the electron density in the bismuth surrounding, with the characteristic orbital of the stereochemically active lone pair of $6 s^{2}$ electrons clearly visible in Fig. 16a. Interestingly, for the given electron density value, iso-surfaces for three of the neighbouring oxide ions show strong asymmetry, with bulges pointing towards the position of the bismuth cation. This kind of asymmetry can be considered as a reflection of a good degree of covalency and directionality in the bonds between oxygen and bismuth in this system. Fig. 16b shows the analogous iso-surface plot of electron density for the niobium cation and the surrounding oxide ions. In this case all of the iso-surfaces seem to be spherical and featureless. Such a symmetric distribution of electron density might be a manifestation of greater ionicity in the bonds between oxygen and niobium. The lower directionality of the more ionic $\mathrm{Nb}-\mathrm{O}$ interaction seem to favour rotational jumps and likely facilitates the observed dynamics of oxide ions within the niobium octahedra. The greater directionality of the more covalent Bi-O interaction would be less favourable for rotational jumps, which is consistent with the generally higher translational:rotational jump ratio. The greater polarization of electron density seen in the Bi-O interaction, particularly around bismuth, may well be a key feature of long-range oxide ion movement in this system.

\section{Conclusions}

Type-II $\mathrm{Bi}_{3} \mathrm{NbO}_{7}$, has a relatively high nominal vacancy concentration of 0.25 vacancies per cation, albeit half of that in $\delta-\mathrm{Bi}_{2} \mathrm{O}_{3}$, and therefore it might be expected to exhibit significant oxide ion conductivity. Ab initio molecular dynamics calculations for type-II $\mathrm{Bi}_{3} \mathrm{NbO}_{7}$, carried out in the present study, can be used to explain why the experimentally measured ionic conductivity of this compound is several orders of magnitude lower than that in $\delta-\mathrm{Bi}_{2} \mathrm{O}_{3}{ }^{17} \mathrm{~A}$ strong preference for niobium cations to adopt an octahedral coordination environment in type-II $\mathrm{Bi}_{3} \mathrm{NbO}_{7}$ is observed. Consequently, there is a relatively high concentration of oxide 
ion vacancies in the niobium cation surroundings (i.e. lower fractional occupancies for oxide ion sites with niobium nearest neighbours) and much lower vacancy concentration in the bismuth cation neighbourhood (i.e. higher site occupancies for oxide ion sites with exclusively bismuth nearest neighbours). Thus, low vacancy concentration in the bismuth coordination sphere reduces the probability of long-range oxide ion movements, consistent with the low ionic conductivity observed in this system.

Low energy barriers for oxide ion jumps in the $\langle 100\rangle$ direction are observed. However, a good proportion of oxide ions in the niobium coordination sphere show only local movement, collectively resulting in rotational motion of the oxygen octahedra, rather than long-range oxide ion diffusion. This may be associated with lower directionality of the more ionic $\mathrm{Nb}-\mathrm{O}$ interaction. There is evidence in the present study for a degree of polarization of electron density in the Bi-O interaction. Bearing in mind the higher fraction of translational oxide ion movements in the bismuth cation surroundings, this polarization appears to be a key feature of long-range ionic transport in the studied system.

\section{Acknowledgements}

We gratefully acknowledge the National Science Centre Poland for project grant numbers 2012/05/E/ST3/02767 and 2013/09/N/ST3/04326 


\section{References}

1. T. Takahashi, H. Iwahara, Y. Nagai, J. Appl. Electrochem., 1972, 2, 97.

2. H.A. Harwig, Z. Anorg. Allg. Chem., 1978, 444, 151.

3. G. Mairesse, B. Scrosati, A. Magistris, C.M. Mari, G. Mariotto (Eds.), Kluwer Academic Publishers, Dordrecht, 1993, p271.

4. P. Shuk, H.D. Wiemhöfer, U. Guth, W. Göpel, M. Greenblatt, Solid State Ionics, 1996, 89, 179.

5. N.M. Sammes, G.A. Tompsett, H. Näfe, F. Aldinger, J. Eur. Ceram. Soc., 1999, 191801.

6. M. Krynski, W. Wrobel, C.E. Mohn, J.R. Dygas, M. Malys, F. Krok, I. Abrahams, Solid State Ionics, 2014, 264, 49.

7. W. Zhou, D.A. Jefferson, J.M. Thomas, Proc. R. Soc. Lond. A, 1986, 406, 173.

8. C.D. Ling, R.L. Withers, S. Schmid, J.G. Thompson, J. Solid State Chem., 1998, 137, 42.

9. A. Castro, E. Aguado, J.M. Rojo, P. Herrero, R. Enjalbert, J. Galy, Mater. Res. Bull., 1998, 33, 31 .

10. C.D. Ling, M. Johnson, J. Solid State Chem., 2004, 177, 1838.

11. R.L. Withers, C.D. Ling, S. Schmid, Z. Kristallogr., 1999 214, 296.

12. M. Valant, D. Suvorov, J. Am. Ceram. Soc., 2003, 86, 939.

13. X.P. Wang, G. Corbel, S. Kodjikian, Q.F. Fang, P. Lacorre, J. Solid State Chem., 2006 179, 3338 .

14. W. Zhou, J. Solid State Chem. 1992, 101, 1.

15. C.D. Ling, J. Solid State Chem., 1992, 148, 380.

16. C.D. Ling, S. Schmid, P.E.R. Blanchard, V. Petrícek, G.J. McIntyre, N. Sharma, A. Maljuk, A.A. Yaremchenko, V.V. Kharton, M. Gutmann, R.L. Withers, J. Amer. Chem. Soc., 2013, 135, 6477 .

17. I. Abrahams, A. Kozanecka-Szmigiel, F. Krok, W. Wrobel, S.C.M. Chan, J.R. Dygas, Solid State Ionics, 2006, 177, 1761.

18. I. Abrahams, F. Krok, A. Kozanecka-Szmigiel, W. Wrobel, S.C.M. Chan, J.R. Dygas, J. Power Sources, 2007, 173, 788.

19. M. Małys, M. Hołdynski, F. Krok, W.Wróbel , J.R. Dygas, C. Pirovano, R.-N. Vannier, E. Capoen, I. Abrahams, J. Power Sources, 2009, 194, 16.

20. M. Leszczynska, X. Liu, W. Wrobel, M. Malys, J.R. Dygas, S. T. Norberg, S. Hull, F. Krok and I. Abrahams, J. Mater. Chem. A, 2014, 2, 18624.

21. I. Abrahams, F. Krok, W. Wrobel, A. Kozanecka-Szmigiel, and S.C.M. Chan, Solid State Ionics, 2008, 179, 2. 
22. I. Abrahams, F. Krok, M. Struzik and J. R. Dygas, Solid State Ionics, 2008, 179, 1013.

23. M. Krynski, W. Wrobel, J.R. Dygas, J. Wrobel, P. Śpiewak, K.J. Kurzydlowski, F. Krok, I. Abrahams, Solid State Ionics, 2013, 245, 43.

24. G. Kresse, J. Hafner. Phys. Rev. B, 1998, 47, 558.

25. G. Kresse, J. Hafner. Phys. Rev. B, 1994, 49, 14251.

26. G. Kresse, J. Furthmüller, Phys. Rev. B, 1996, 54, 11169.

27. G. Kresse, J. Furthmüller, Comp. Mater. Sci., 1996, 6, 15.

28. J. Perdew, K. Burke, M. Ernzerhof, Phys. Rev. Lett., 1996, 77, 3865.

29. G. Kresse, J. Joubert, Phys. Rev. B, 1999, 59, 1758.

30. H. Hellmann, Einführung in “Die Quantenchemie, Franz Deuticke”, Leipzig, 1937.

31. R. Feynman, Phys. Rev., 1939, 56, 340.

32. S. Nosé, J. Chem. Phys., 1984, 81, 511.

33. W. Hoover, Phys. Rev. A, 1985, 31, 1695.

34. H.J. Monkhorst, J.D. Pack, Phys. Rev. B, 1976, 13, 5188.

35. C.E. Mohn, S. Stølen, S.T. Norberg, S. Hull, Phys. Rev. Lett., 2009, 102, 155502.

36. R.D. Shannon, Acta Crystallogr. A, 1976, 32, 751.

37. See for example K. Kato, Acta Crystallogr. B, 1976, 32, 764.

38. I. Abrahams, X. Liu, S. Hull, S.T. Norberg, F. Krok, A. Kozanecka-Szmigiel, M. S. Islam, S.J. Stokes, Chem. Mater., 2010, 22, 4435.

39. D. Marrocchelli, P.A. Madden, S. T. Norberg, S. Hull, J. Phys.: Condens. Matter, 2009, 21, 405403.

40. E. Aguado, R. Enjalbert, J. M. Rojo, A. Castro, Bol. Soc. Esp. Ceram. V., 1995, 34, 417. 
Table 1

Average contact distances $(\AA)$ between metal and oxygen atoms and average coordination numbers $(\mathrm{CN})$ for $\mathrm{Bi}_{3} \mathrm{NbO}_{7}$ at $1223 \mathrm{~K}$ calculated in the present study compared to those calculated from crystallographic parameters. Calculations assume maximum Bi-O and $\mathrm{Nb}-\mathrm{O}$ distances of 3.4 and $2.9 \AA$ A, respectively. CN M stands for average cation coordination number.

\begin{tabular}{|l|l|l|l|l|l|l|l|l|l|}
\hline $\mathrm{Mol}^{2} \mathrm{Nb}_{2} \mathrm{O}_{5}$ & $\begin{array}{l}\text { Structure } \\
\text { Type }\end{array}$ & Temp K & $\mathrm{Bi}-\mathrm{O}$ & $\mathrm{Nb}-\mathrm{O}$ & $\mathrm{M}-\mathrm{O}$ & $\mathrm{CN}$ Bi & $\mathrm{CN} \mathrm{Nb}$ & $\mathrm{CN}$ M & Ref. \\
\hline 0.25 & II & 1223 & $\begin{array}{l}2.26^{\mathrm{a}} \\
2.31^{\mathrm{b}}\end{array}$ & $\begin{array}{l}1.95^{\mathrm{a}} \\
2.08^{\mathrm{b}}\end{array}$ & $\begin{array}{l}2.18^{\mathrm{a}} \\
2.27^{\mathrm{b}}\end{array}$ & 7.18 & 6.01 & 6.9 & $\begin{array}{l}\text { This } \\
\text { work }\end{array}$ \\
\hline 0.25 & II & 298 & & & 2.38 & & & 7.1 & 17 \\
\hline 0.25 & II & 1073 & & & 2.55 & & & 7.0 & 17 \\
\hline 0.25 & II & 298 & & & 2.39 & & & 7.0 & 40 \\
\hline 0.254 & III & Ambient & 2.49 & 2.01 & 2.39 & 7.35 & 6.00 & 6.9 & 15 \\
\hline
\end{tabular}

${ }^{\mathrm{a}}$ Modal value

${ }^{\mathrm{b}}$ Mean value

Table 2

Total number of oxide ion jumps (rotational and translational) involving oxide ions in the coordination spheres of niobium and bismuth, calculated over the total simulation time at the studied temperatures.

\begin{tabular}{|c|c|c|c|c|}
\hline & $1223 \mathrm{~K}$ & $1273 \mathrm{~K}$ & $1323 \mathrm{~K}$ & $1373 \mathrm{~K}$ \\
\hline $\mathrm{Nb}$ & 93 & 119 & 136 & 149 \\
\hline $\mathrm{Bi}$ & 27 & 36 & 40 & 47 \\
\hline
\end{tabular}


Figures.

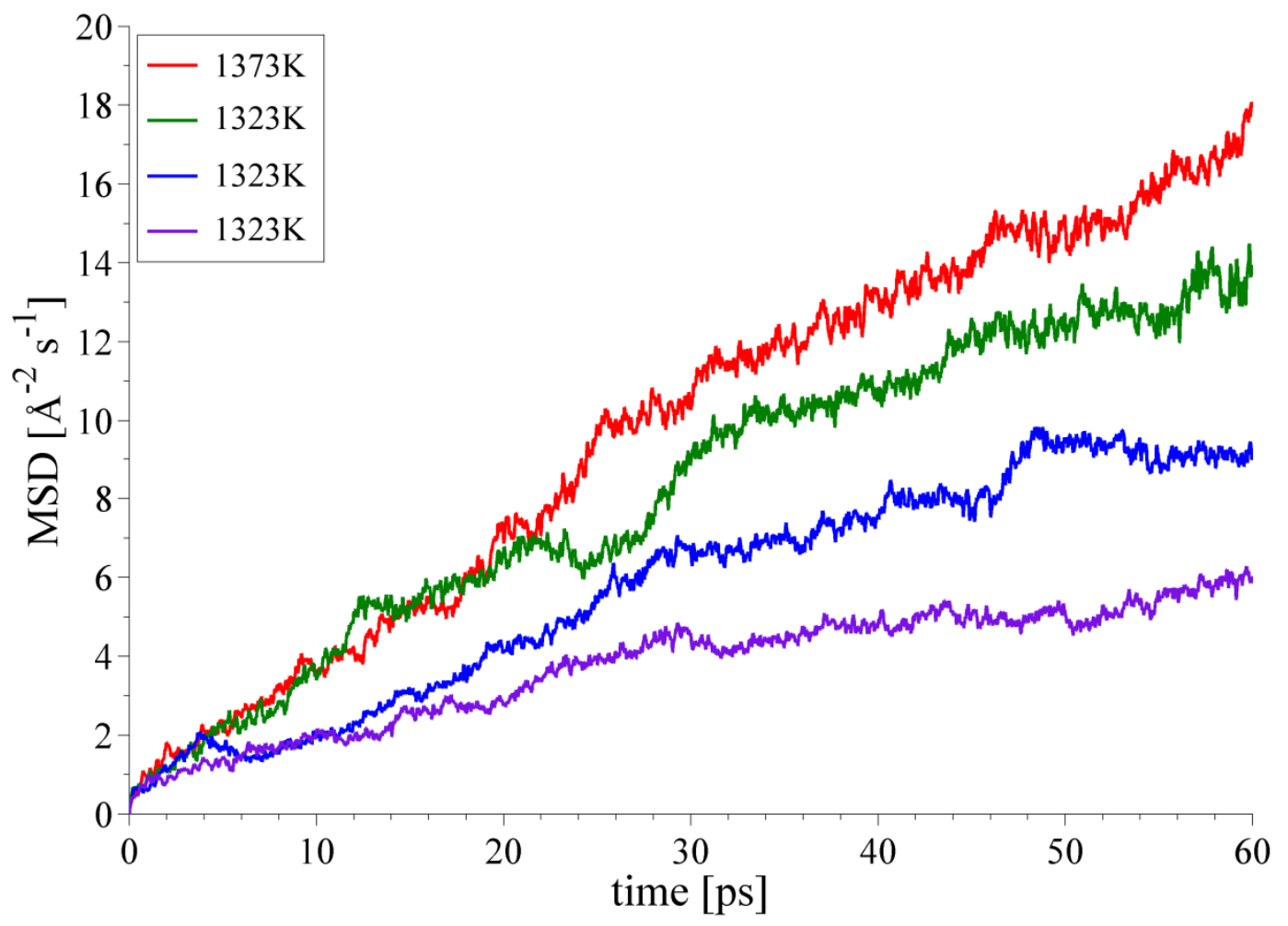

Fig. 1. Variation of oxide ion mean square displacement (MSD) with simulation time for type-II $\mathrm{Bi}_{3} \mathrm{NbO}_{7}$ system at the studied temperatures. 


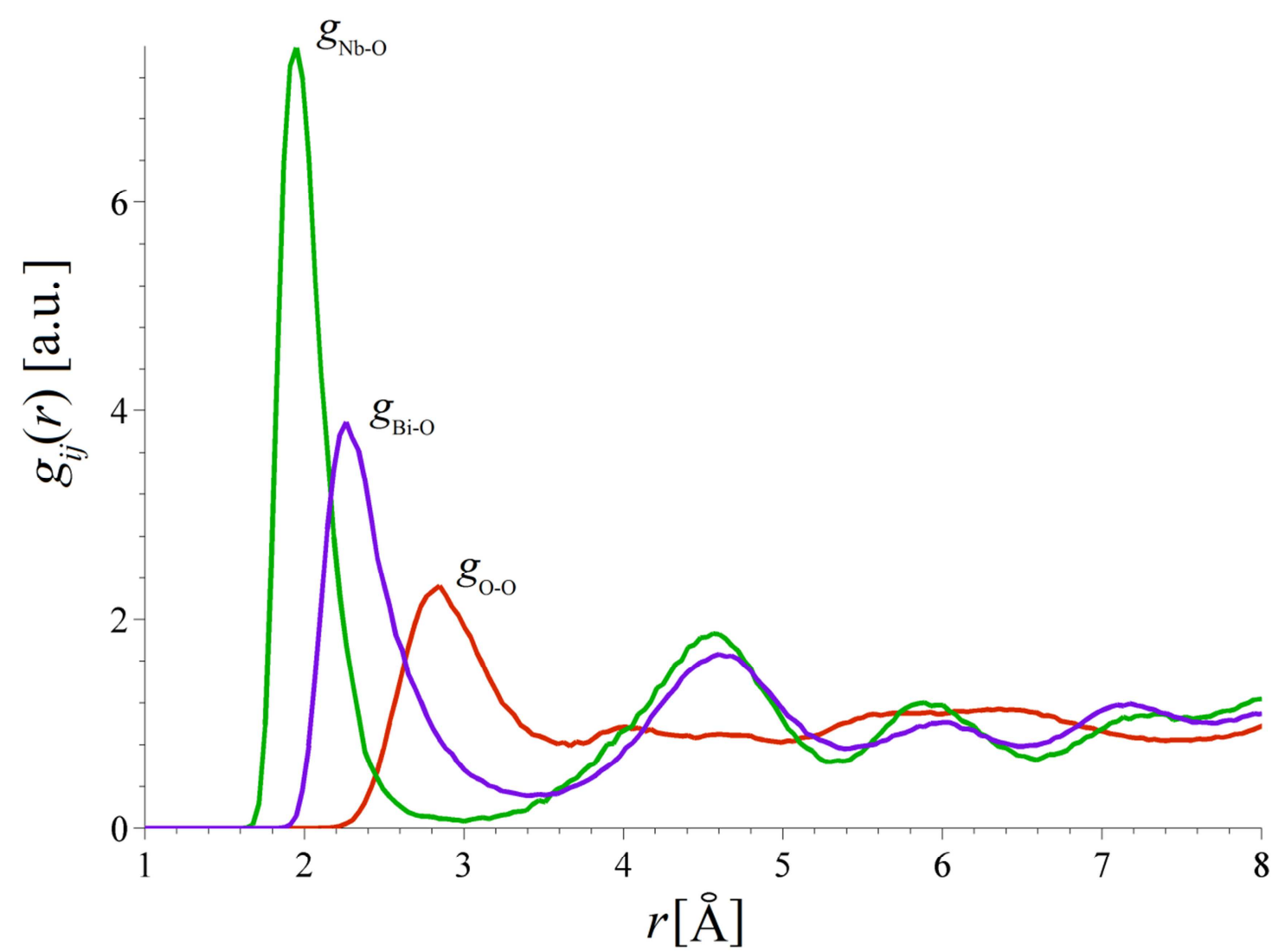

Fig. 2. Individual pair distribution functions $g_{i-j}(r)$ for type-II $\mathrm{Bi}_{3} \mathrm{NbO}_{7}$ at $1223 \mathrm{~K}$, showing $g_{\mathrm{Nb}-\mathrm{O}}(r)$ (green), $g_{\mathrm{Bi}-\mathrm{O}}(r)$ (violet) and $g_{\mathrm{O}-\mathrm{O}}(r)$ (red) correlations. 
(a)

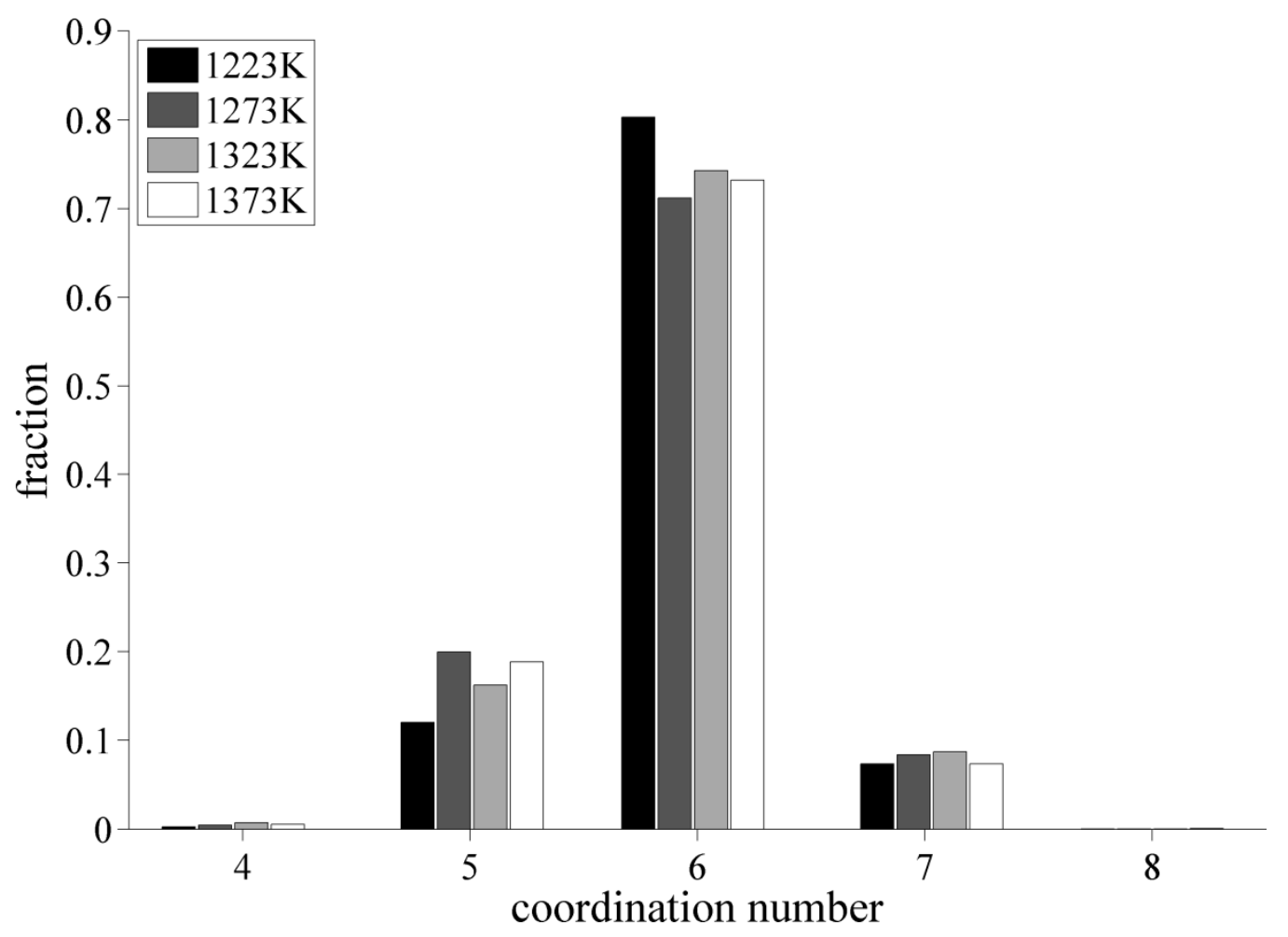

(b)

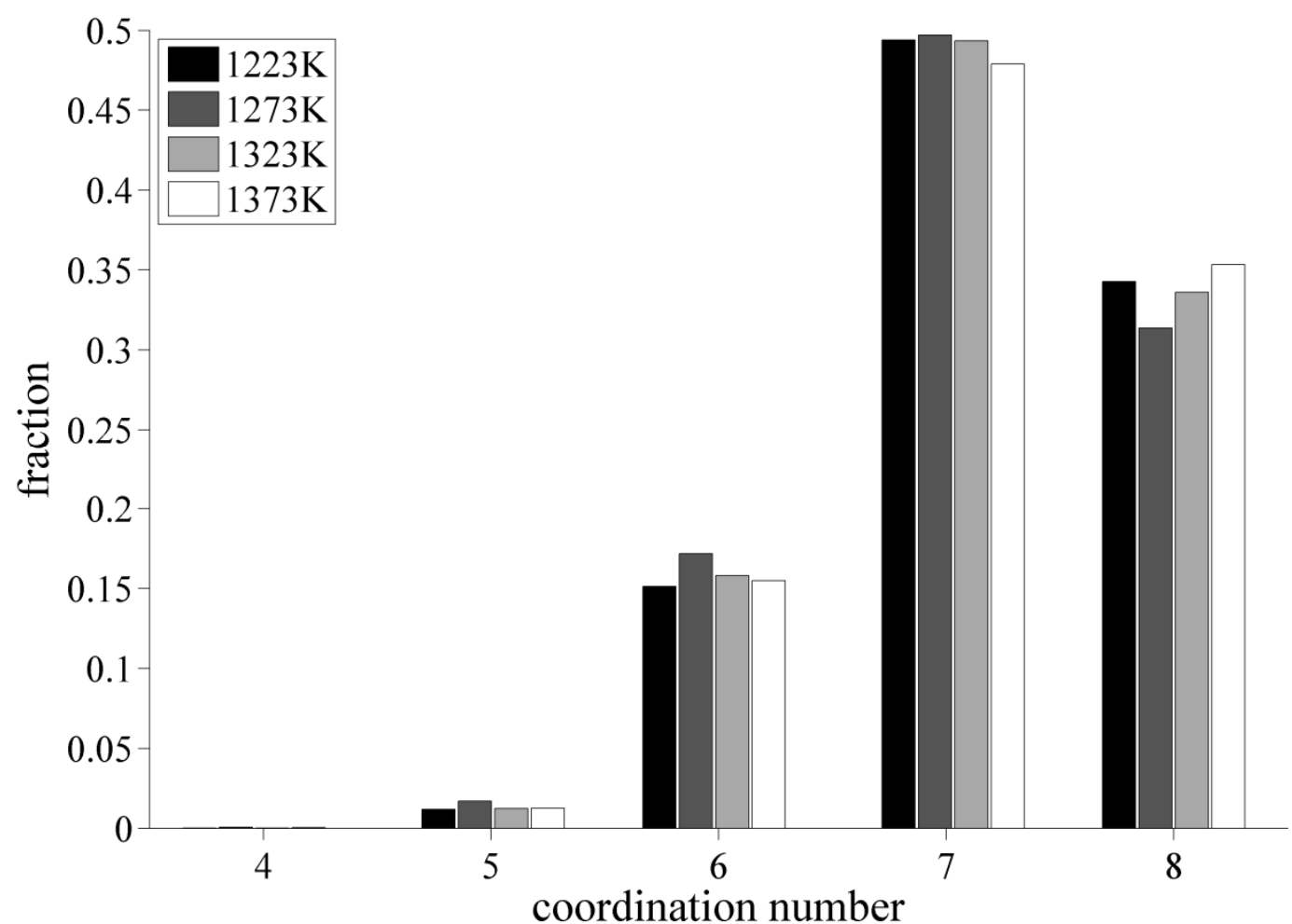

Fig. 3. Fractional coordination numbers in type-II $\mathrm{Bi}_{3} \mathrm{NbO}_{7}$ calculated for (a) $\mathrm{Nb}^{5+}$ cations and $(b) \mathrm{Bi}^{3+}$ cations at investigated temperatures. 
(a)

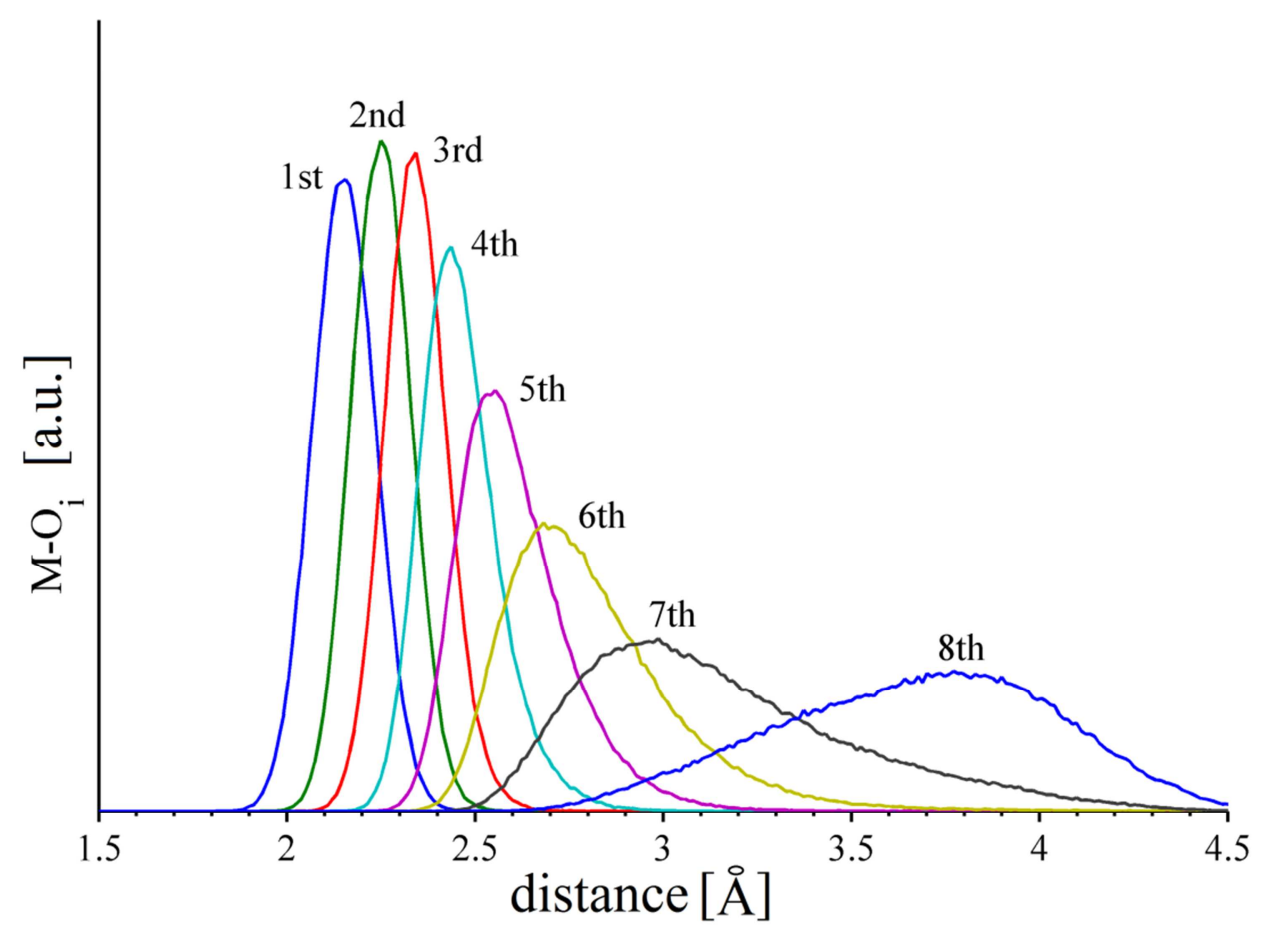

(b)

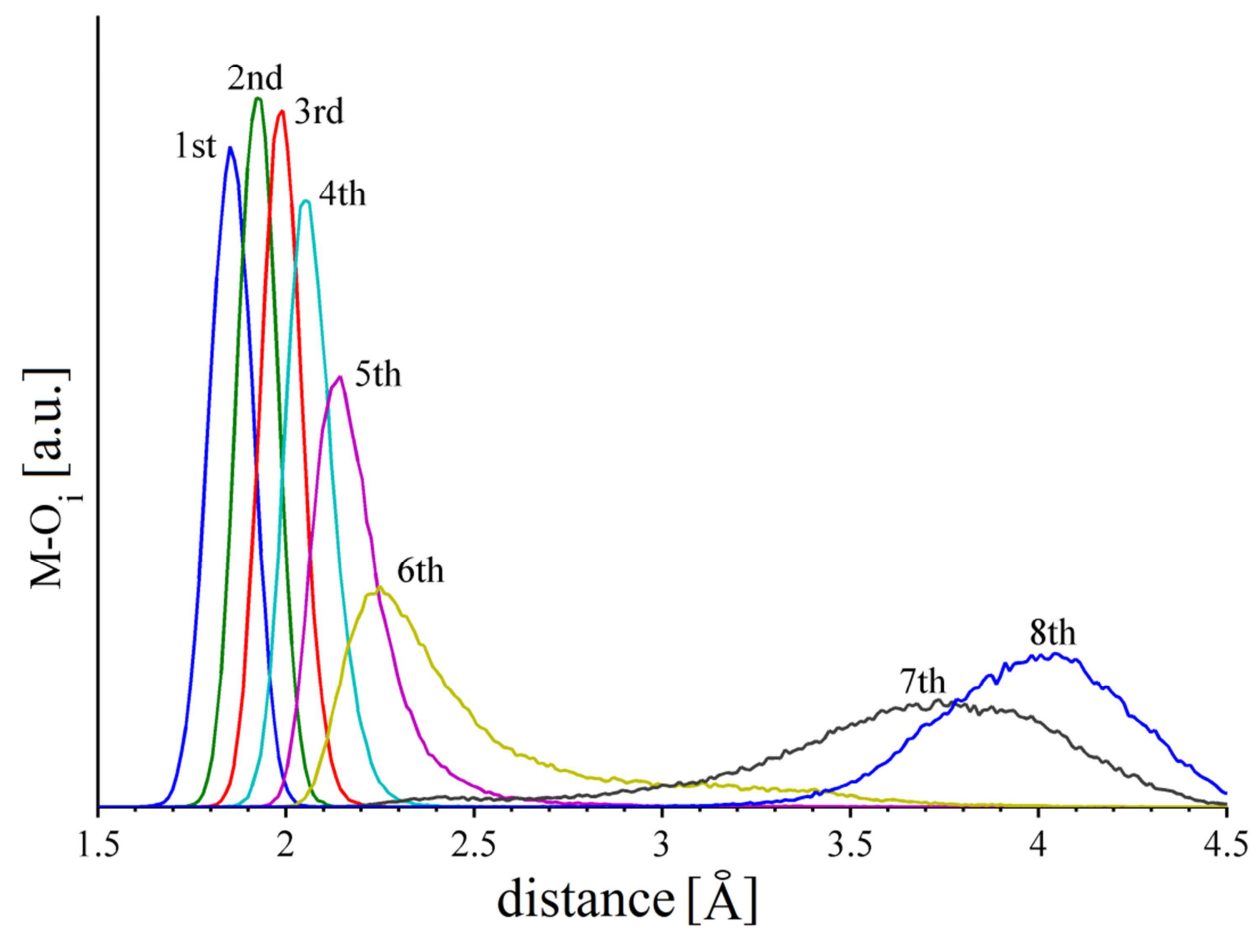

Fig. 4. $\mathrm{M}-\mathrm{O}_{i}$ contact distance distributions for the eight closest oxide ions for type-II $\mathrm{Bi}_{3} \mathrm{NbO}_{7}$ at $1223 \mathrm{~K}(i=1$ to 8$)$; (a) $\mathrm{M}=\mathrm{Bi}$ and (b) $\mathrm{M}=\mathrm{Nb}$. 


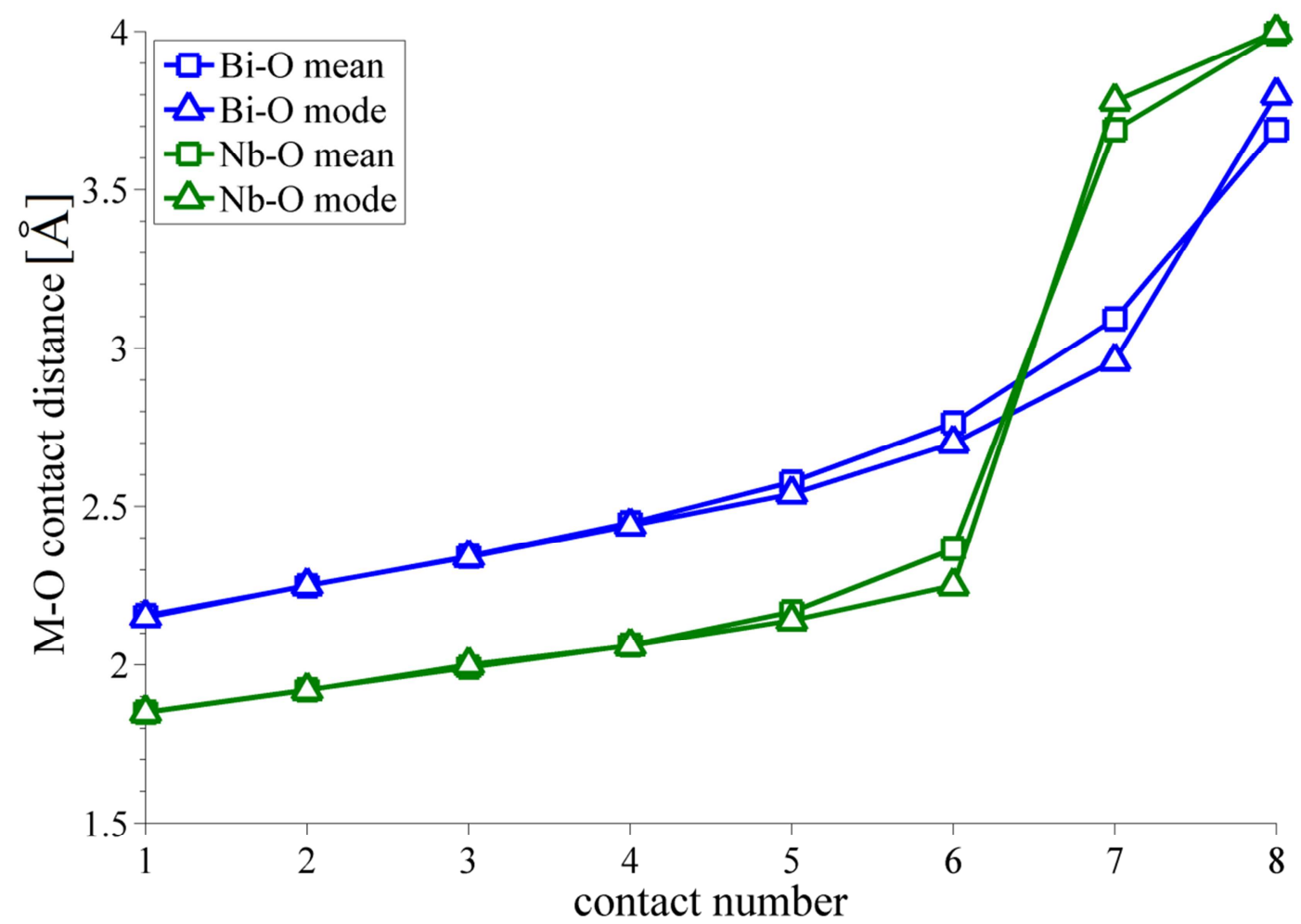

Fig. 5. Mean and modal $\mathrm{M}-\mathrm{O}(\mathrm{M}=\mathrm{Bi}$ and $\mathrm{Nb})$ contact distances for the closest eight oxide ions in type-II $\mathrm{Bi}_{3} \mathrm{NbO}_{7}$ at $1223 \mathrm{~K}$. 


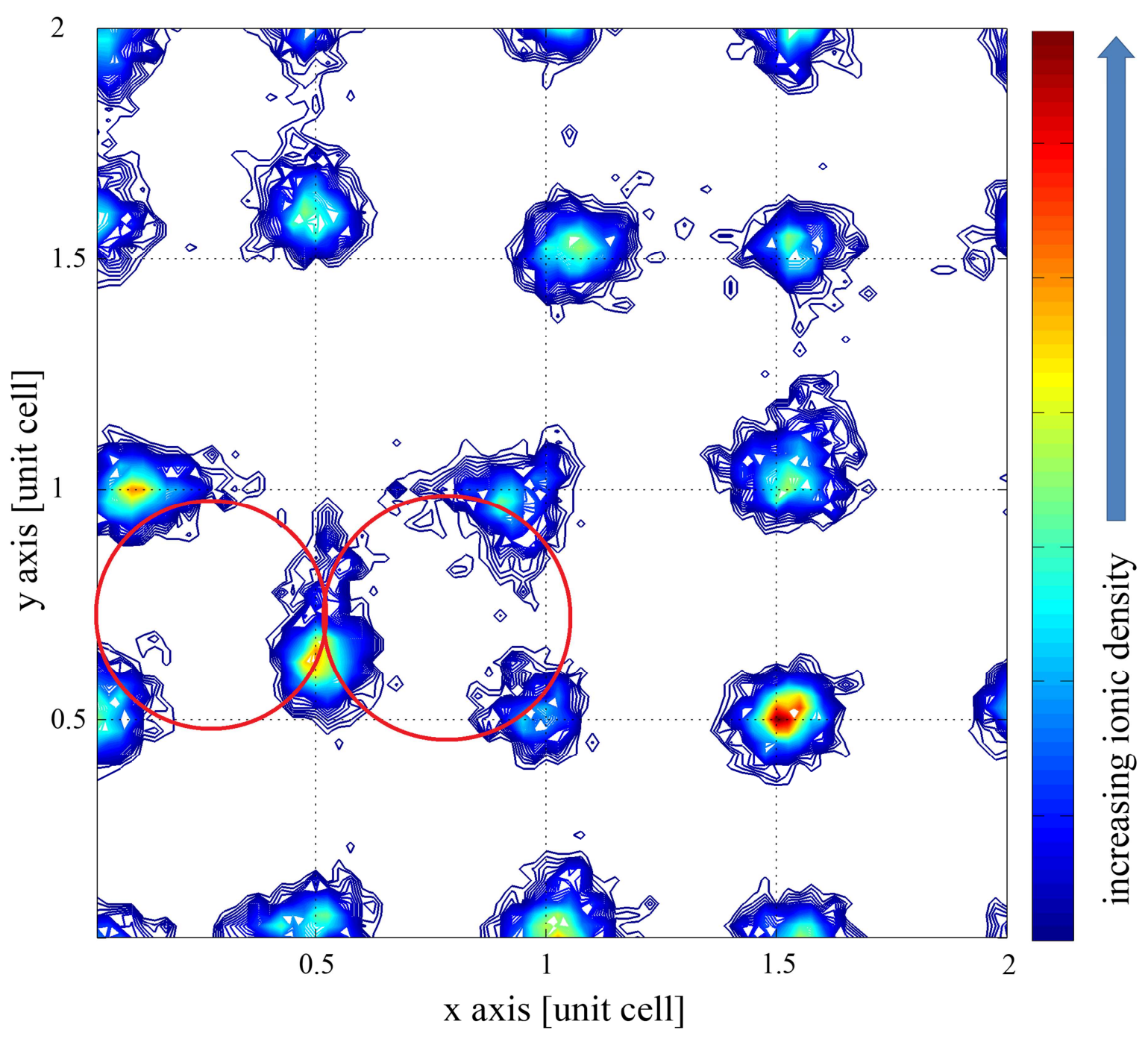

Fig. 6. Oxide ion density cross section through $<110>$ plane in type-II $\mathrm{Bi}_{3} \mathrm{NbO}_{7}$ at 1223 K. Niobium cation environments are marked by red circles. Positions of $8 c$ sites are indicated by the intersections of the dashed lines. 
(a)

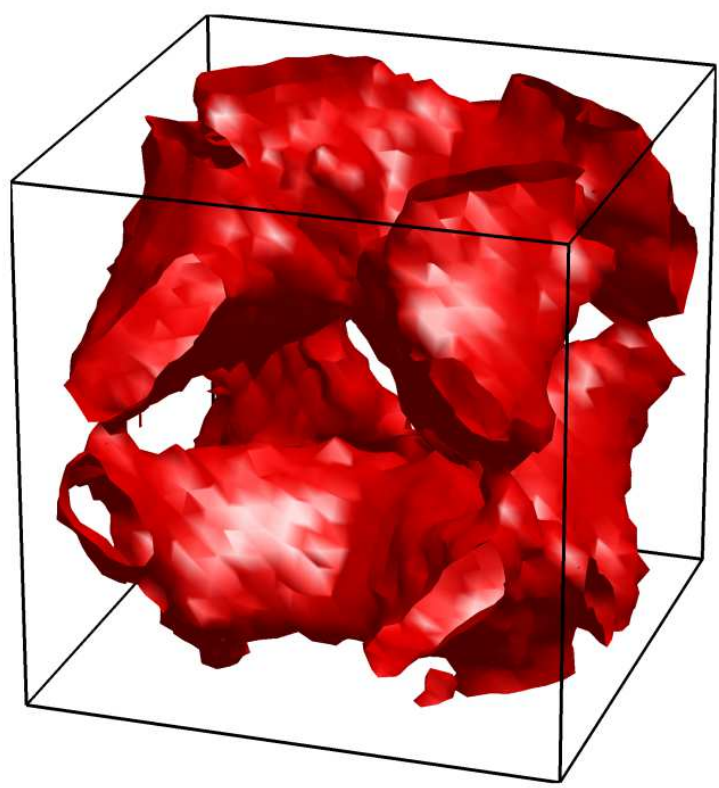

(b)

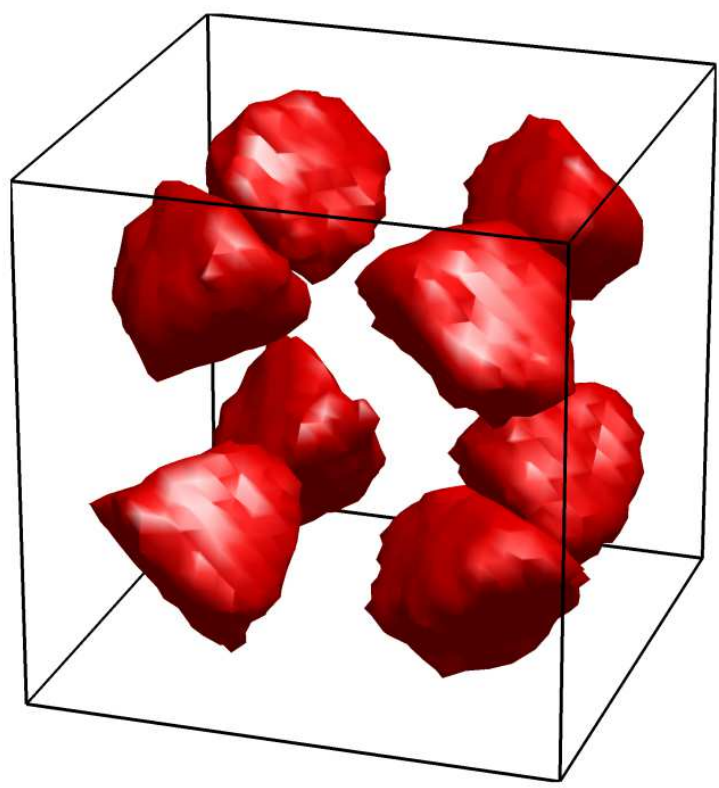

Fig. 7. Iso-surface representation of oxide ion density in (a) type-II-Bi ${ }_{3} \mathrm{NbO}_{7}$ and (b) $\delta-\mathrm{Bi}_{3} \mathrm{YO}_{6}$ (data for the latter derived from reference 23 ). 


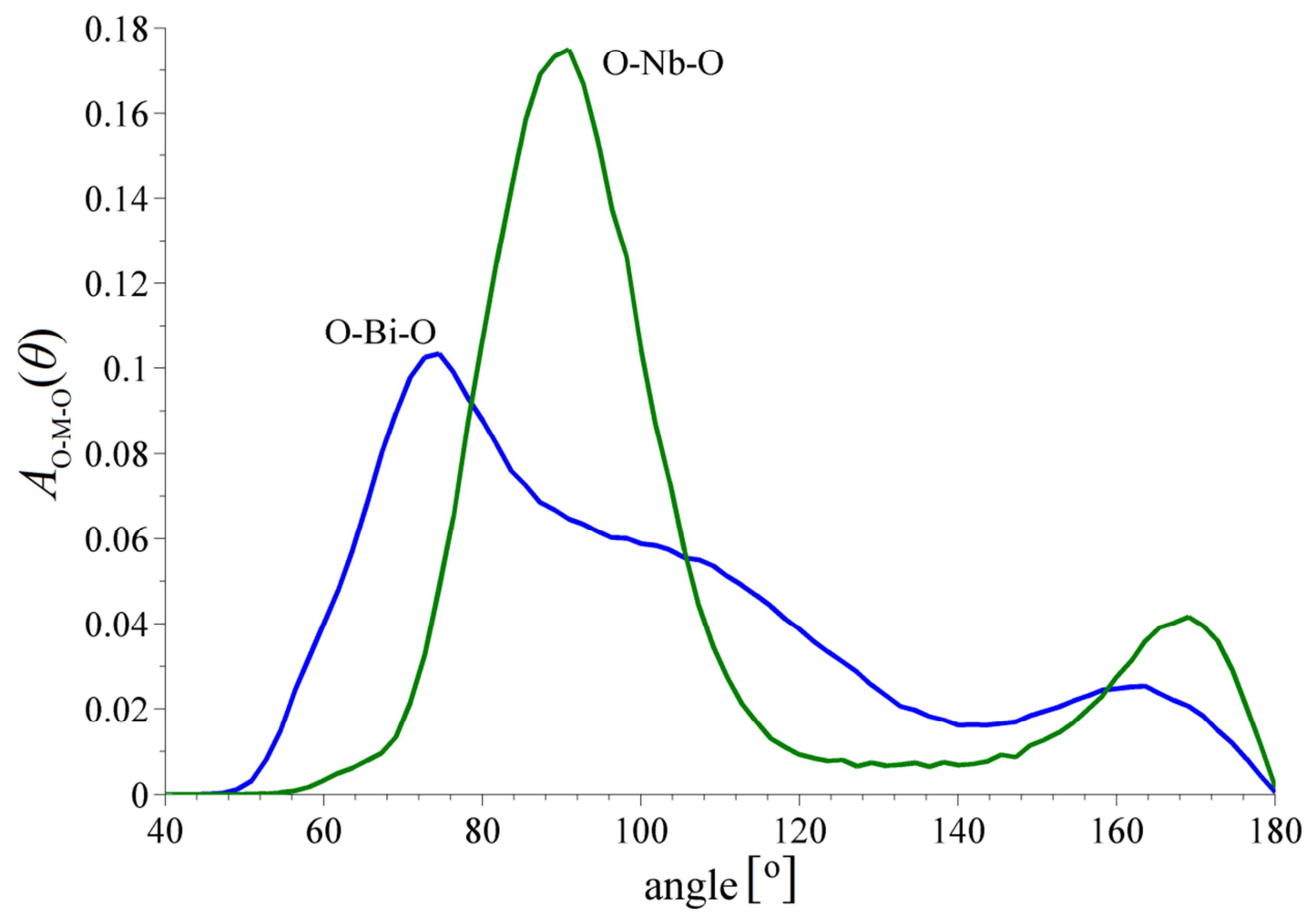

Fig. 8. Angular distribution functions $A_{\mathrm{O}-\mathrm{M}-\mathrm{O}}(\theta)$ for type-II $\mathrm{Bi}_{3} \mathrm{NbO}_{7}$ at $1223 \mathrm{~K}$.

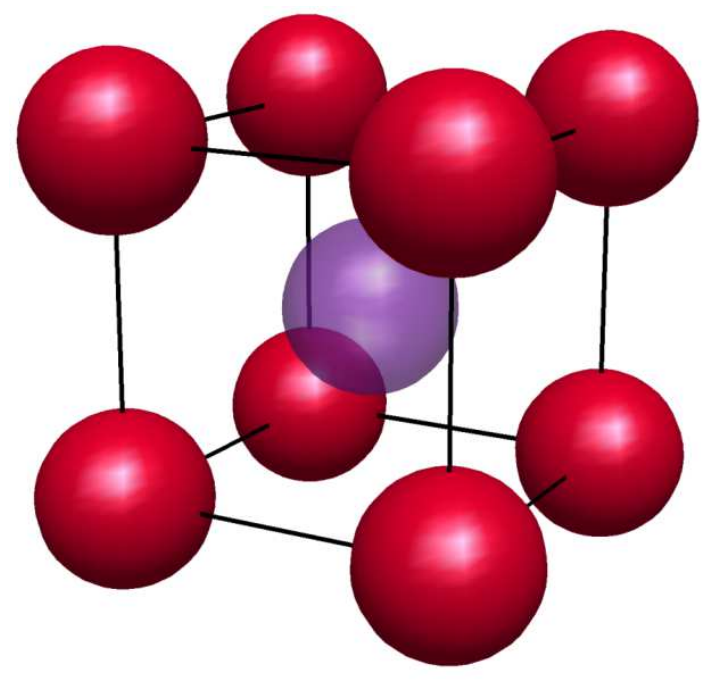

(a)

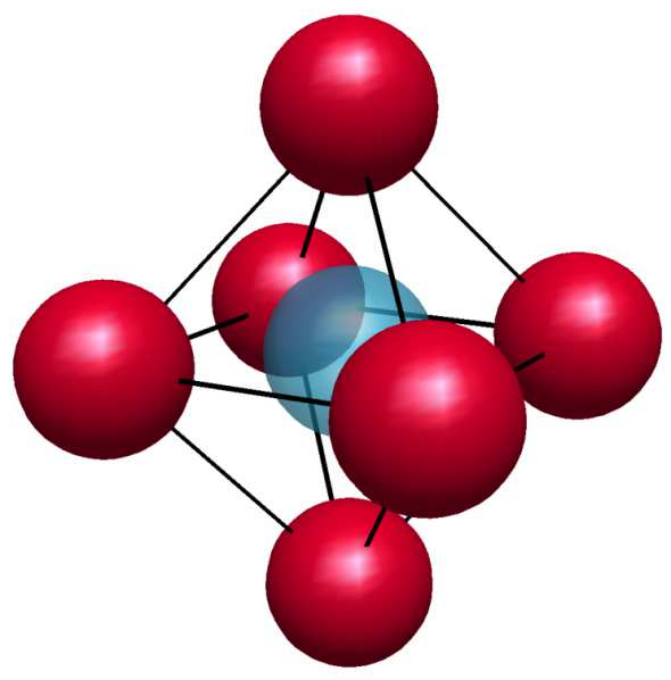

(b)

Fig. 9. Schematic representation of (a) eight-fold cubic and (b) six-fold octahedral cation coordination environments. Blue, violet and red spheres represent niobium, bismuth and oxygen atoms respectively. 


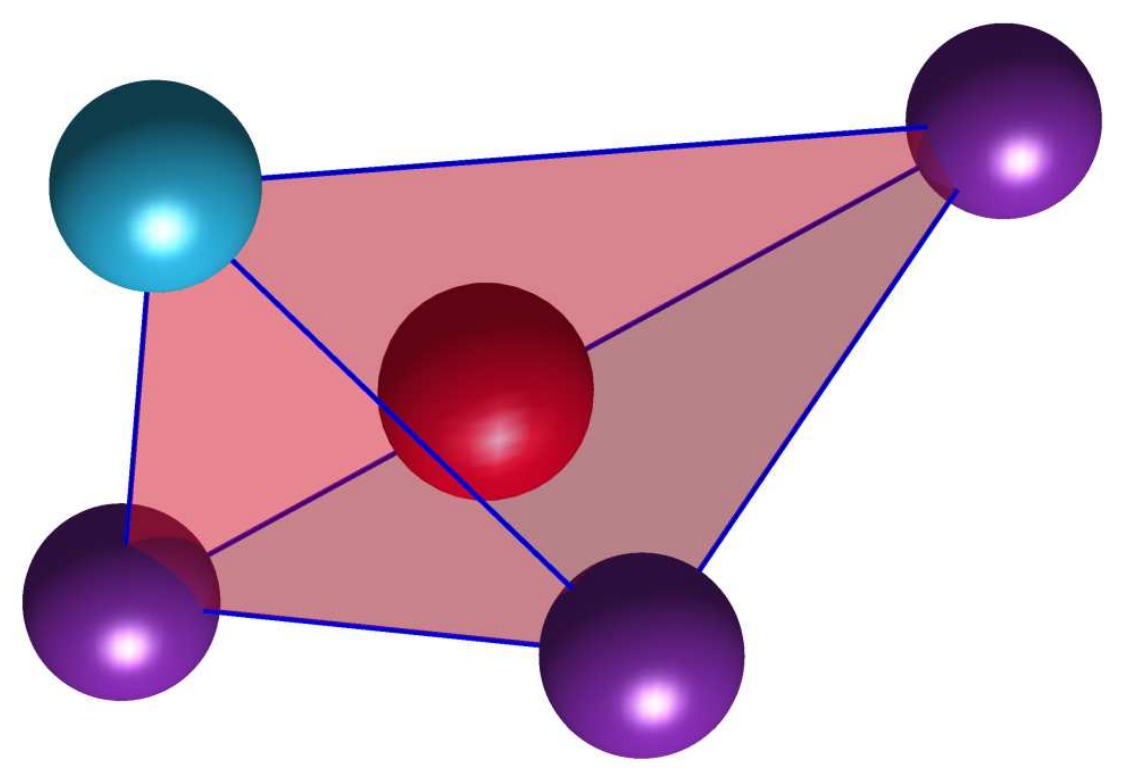

Fig. 10. Typical oxide ion site in type-II $\mathrm{Bi}_{3} \mathrm{NbO}_{7}$, calculated as the centre of gravity between four neighbouring cations. Blue and violet spheres represent niobium and bismuth cations respectively, with the oxide ion represented by a red sphere.

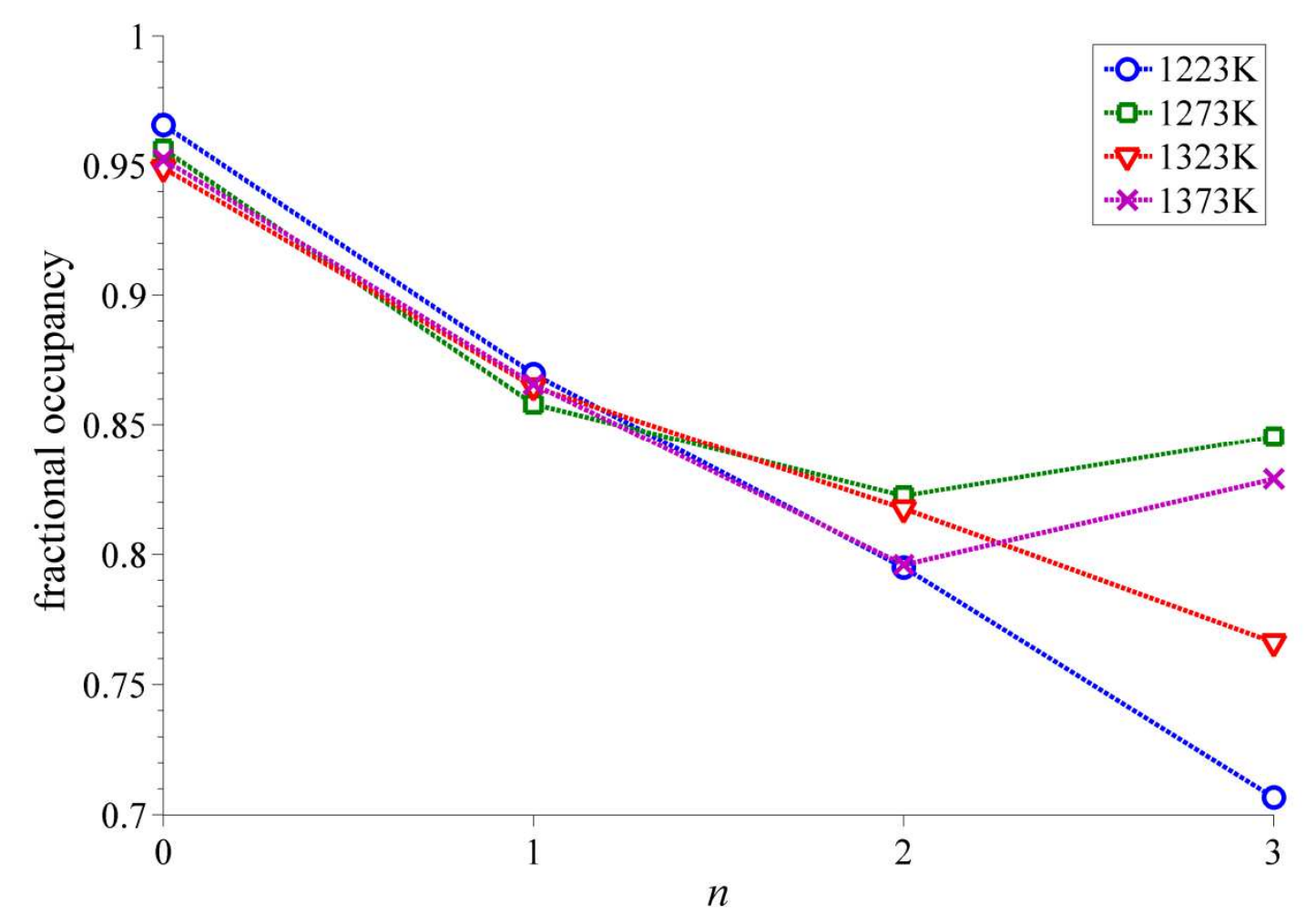

Fig. 11. Oxide ion site occupancy in type-II $\mathrm{Bi}_{3} \mathrm{NbO}_{7}$ for sites with $4-n \mathrm{Bi}^{3+}$ and $n \mathrm{Nb}^{5+}$ cations at the studied temperatures. 


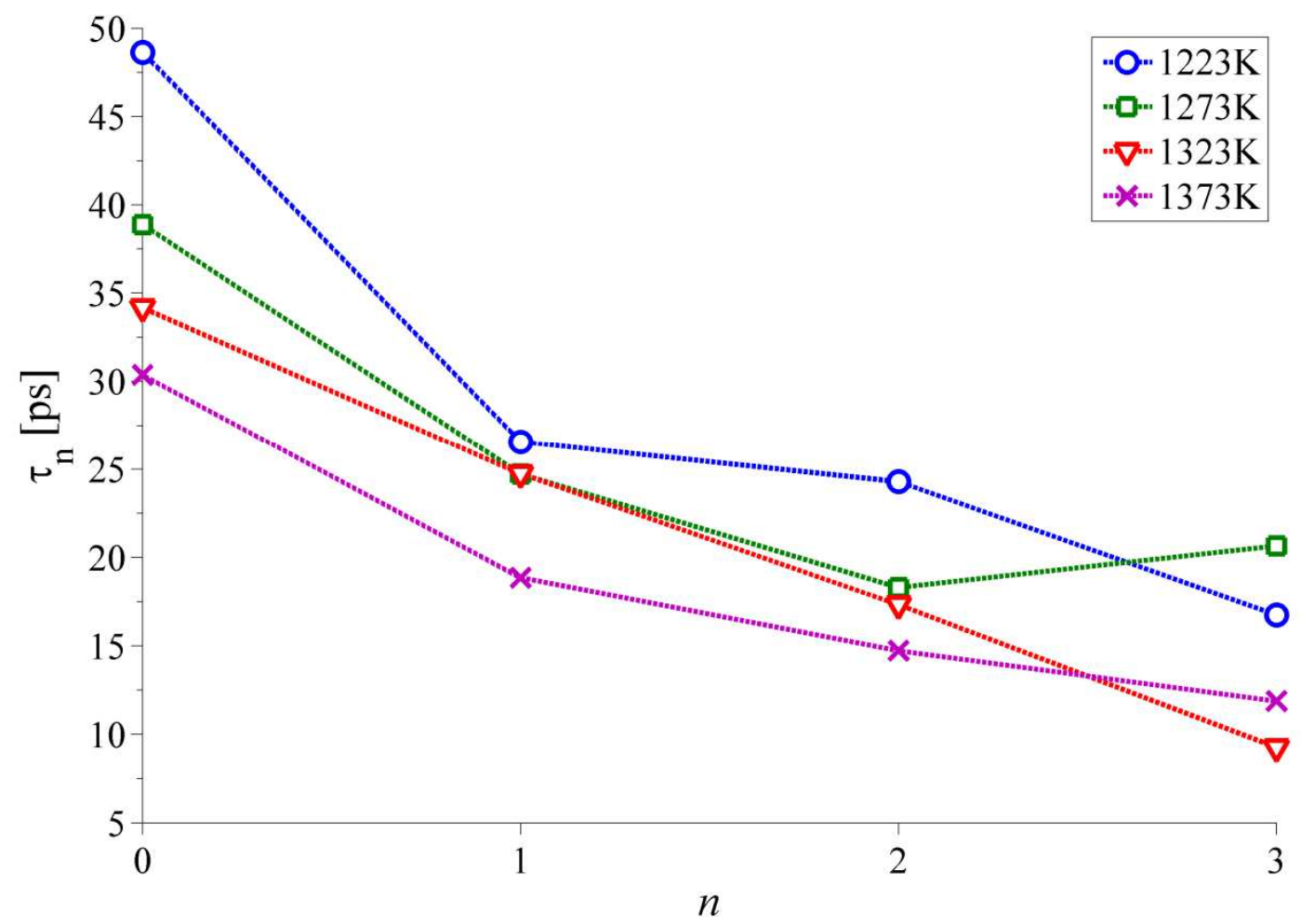

Fig. 12. Average oxide ion site residence time $\left(\tau_{n}\right)$ in type-II $\mathrm{Bi}_{3} \mathrm{NbO}_{7}$ for sites with $4-n$ $\mathrm{Bi}^{3+}$ and $n \mathrm{Nb}^{5+}$ cations at the studied temperatures. 
a)

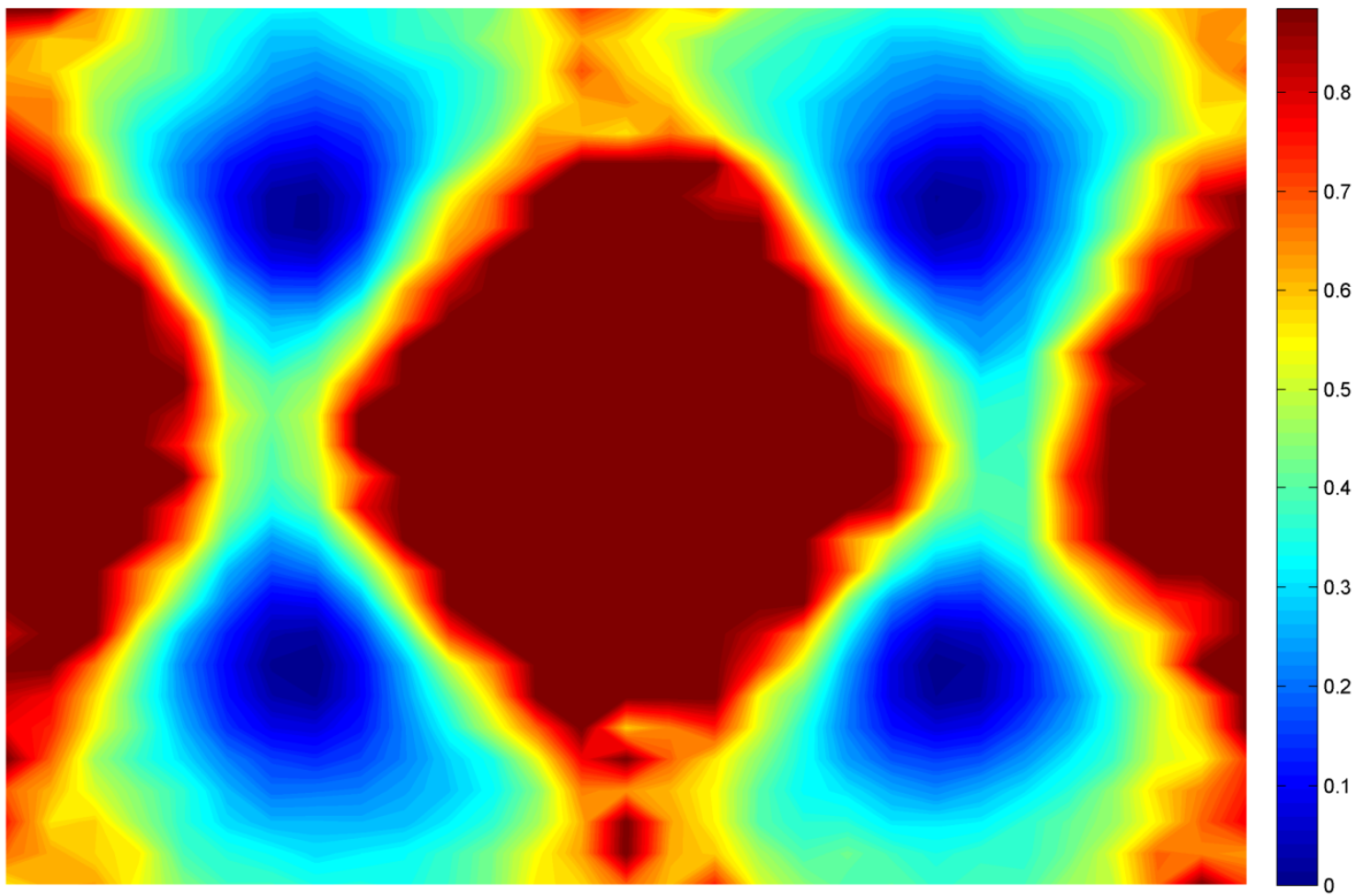

b)

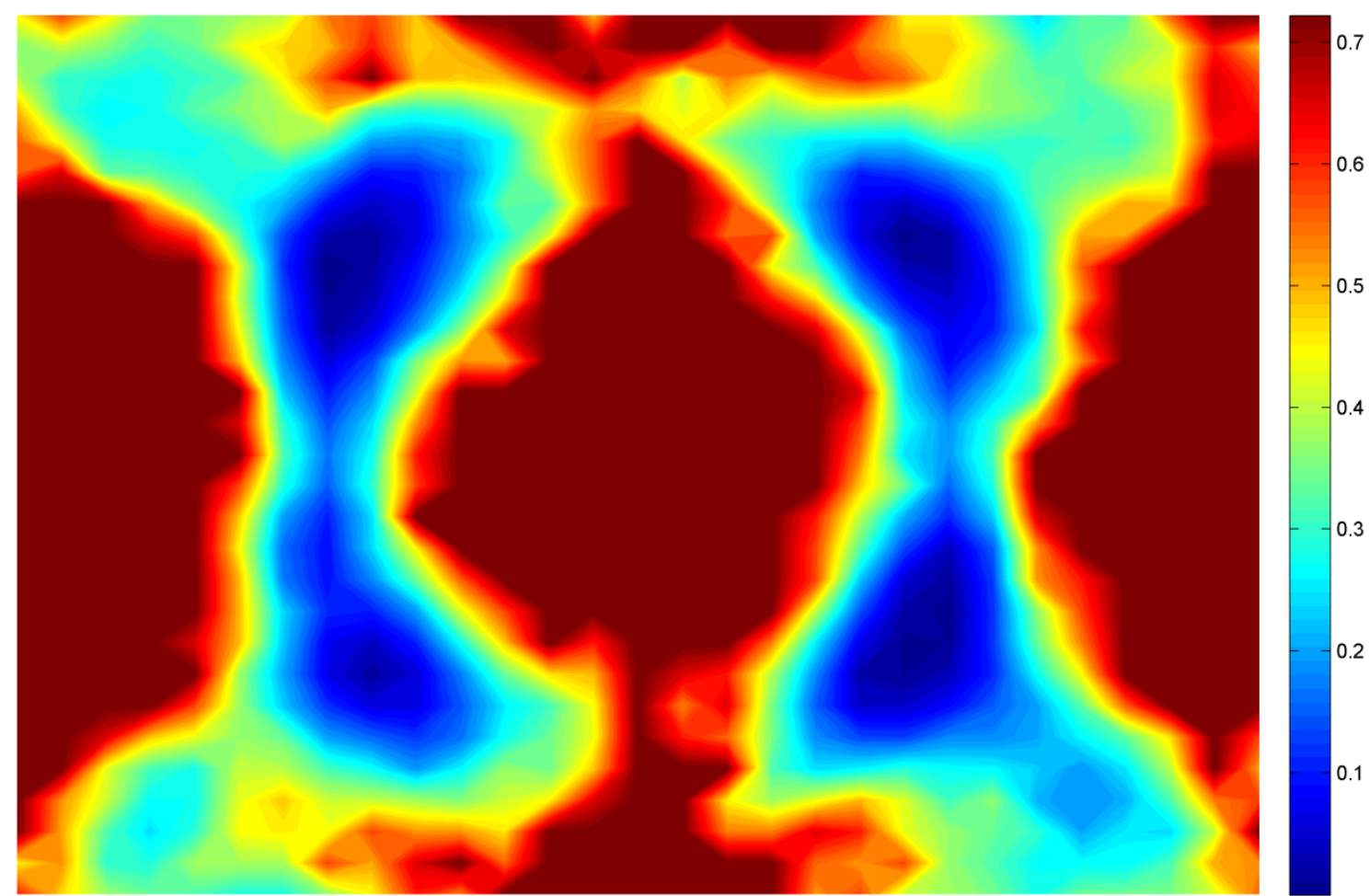

Fig. 13. Contour plots showing energy landscape around (a) bismuth and (b) niobium cations in the $\langle 110\rangle$ plane for type-II $\mathrm{Bi}_{3} \mathrm{NbO}_{7}$ at $1223 \mathrm{~K}$. 


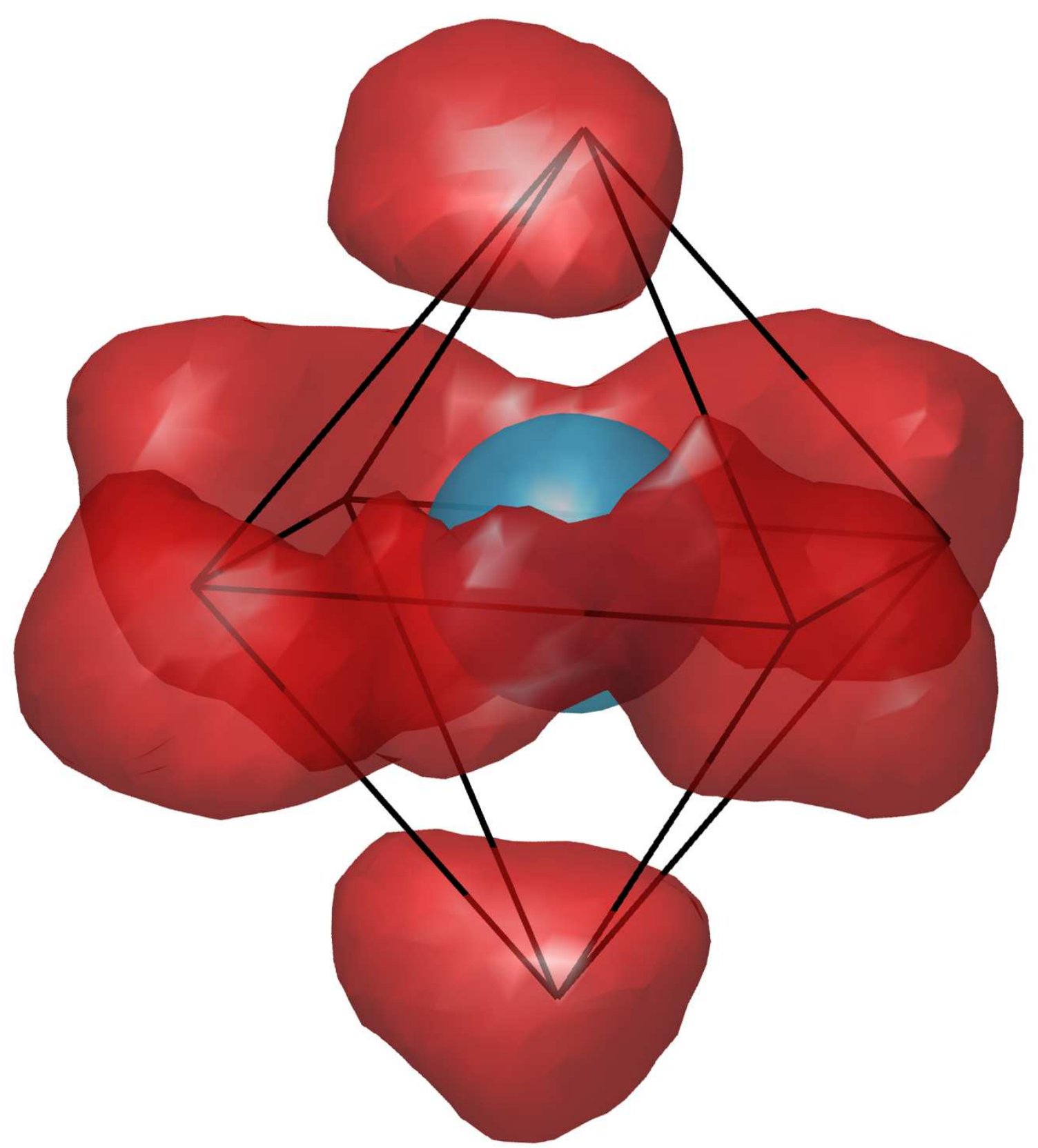

Fig. 14. Isosurface representation of oxide ion density around a typical niobium cation (blue sphere) in type-II $\mathrm{Bi}_{3} \mathrm{NbO}_{7}$ at $1223 \mathrm{~K}$. The octahedral coordination polyhedron around $\mathrm{Nb}^{5+}$ is indicated by black lines. 


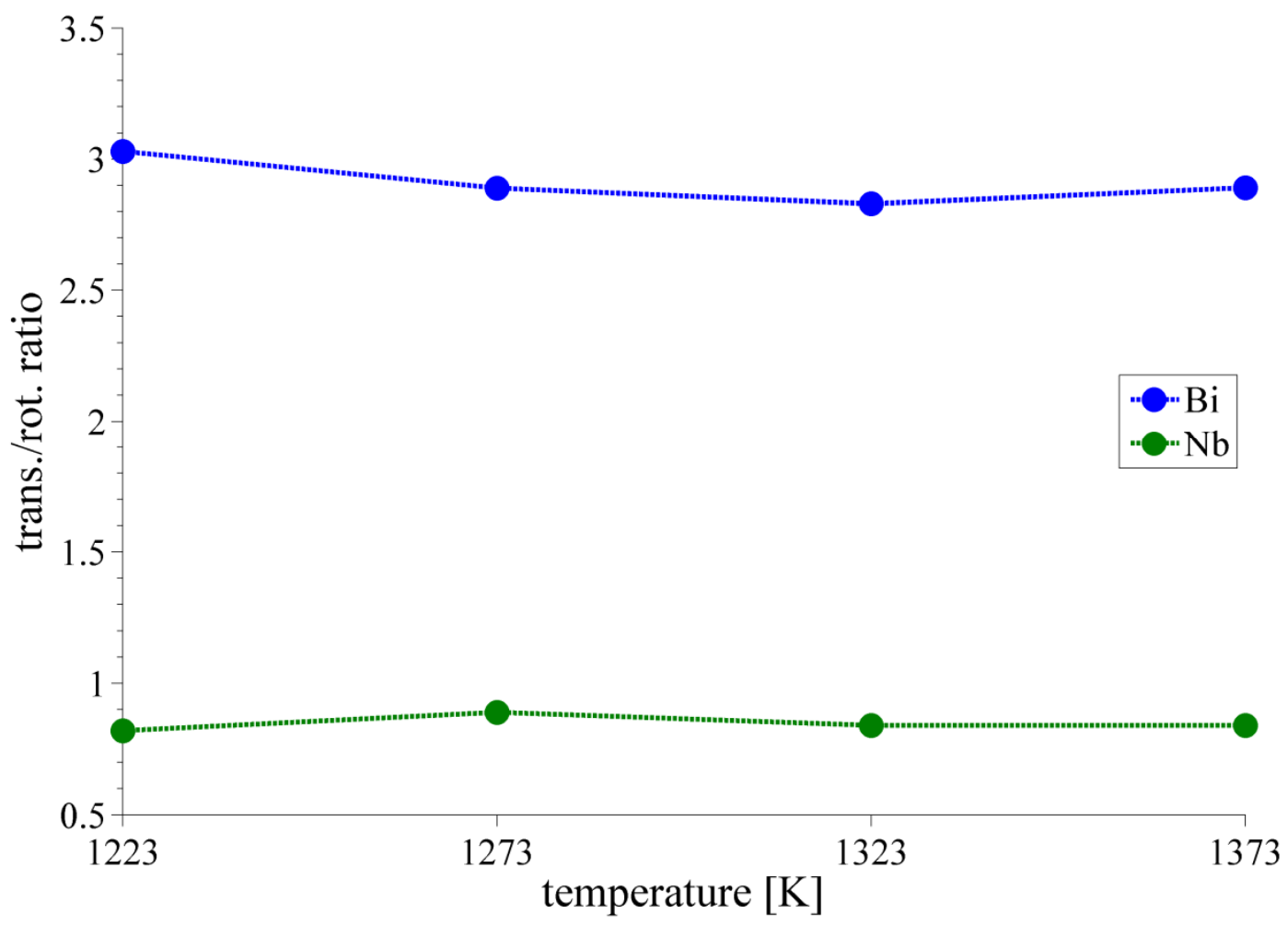

Fig. 15. Ratio of translational to rotational jumps of oxide ions associated with bismuth and niobium cations in type-II $\mathrm{Bi}_{3} \mathrm{NbO}_{7}$ at the studied temperatures.

a)
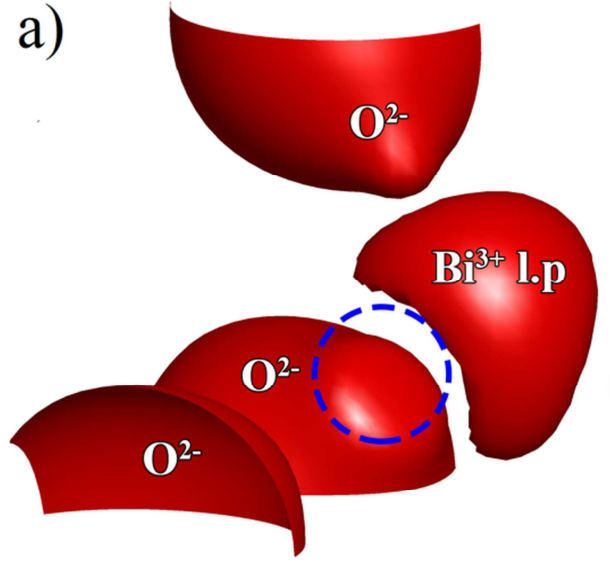
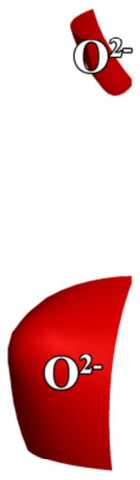

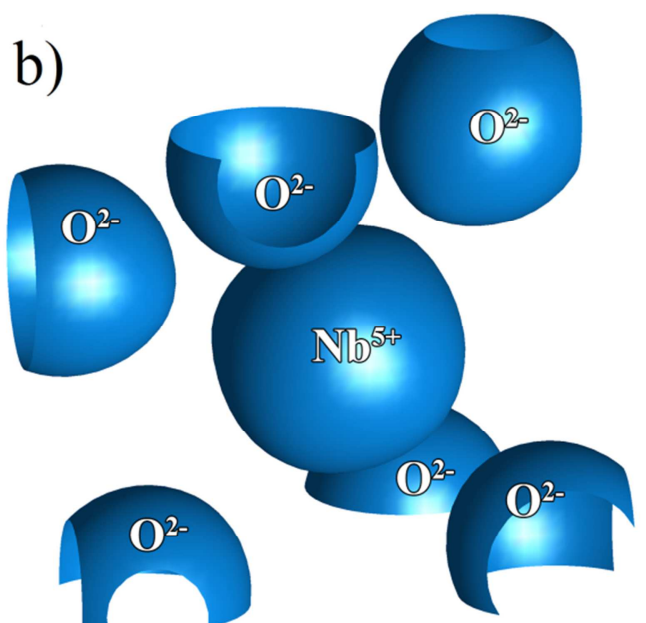

Fig. 16. Electron density iso-surfaces for type-II $\mathrm{Bi}_{3} \mathrm{NbO}_{7}$ at $1223 \mathrm{~K}$ showing a) bismuth and b) niobium cation surroundings. $\mathrm{Bi}^{3+}$ l.p corresponds to the bismuth lone pair orbital and the dashed circle represents the bismuth ion core (not presented for clarity). 